OPEN ACCESS

Edited by:

Anca Dana Dobrian,

Eastern Virginia Medical School,

United States

Reviewed by:

Takayuki Anazawa,

Kyoto University, Japan

Gumpei Yoshimatsu,

Fukuoka University, Japan

${ }^{*}$ Correspondence:

Eiji Yoshihara

eiji.yoshihara@/undquist.org

Specialty section:

This article was submitted to Diabetes: Molecular Mechanisms, a section of the journal

Frontiers in Endocrinology

Received: 29 June 2021 Accepted: 13 August 2021 Published: 13 September 2021

Citation:

Cayabyab F, Nih LR and Yoshihara E (2021) Advances in Pancreatic Islet Transplantation Sites for the Treatment of Diabetes.

Front. Endocrinol. 12:732431. doi: 10.3389/fendo.2021.732431

\section{Advances in Pancreatic Islet Transplantation Sites for the Treatment of Diabetes}

\author{
Fritz Cayabyab ${ }^{1}$, Lina R. Nih ${ }^{1,2}$ and Eiji Yoshihara ${ }^{1,2 *}$ \\ ${ }^{1}$ Lundquist Institute for Biomedical Innovation at Harbor-UCLA Medical Center, Torrance, CA, United States, ${ }^{2}$ David Geffen \\ School of Medicine at University of California, Los Angeles, CA, United States
}

Diabetes is a complex disease that affects over 400 million people worldwide. The life-long insulin injections and continuous blood glucose monitoring required in type 1 diabetes (T1D) represent a tremendous clinical and economic burdens that urges the need for a medical solution. Pancreatic islet transplantation holds great promise in the treatment of T1D; however, the difficulty in regulating post-transplantation immune reactions to avoid both allogenic and autoimmune graft rejection represent a bottleneck in the field of islet transplantation. Cell replacement strategies have been performed in hepatic, intramuscular, omentum, and subcutaneous sites, and have been performed in both animal models and human patients. However more optimal transplantation sites and methods of improving islet graft survival are needed to successfully translate these studies to a clinical relevant therapy. In this review, we summarize the current progress in the field as well as methods and sites of islet transplantation, including stem cell-derived functional human islets. We also discuss the contribution of immune cells, vessel formation, extracellular matrix, and nutritional supply on islet graft survival. Developing new transplantation sites with emerging technologies to improve islet graft survival and simplify immune regulation will greatly benefit the future success of islet cell therapy in the treatment of diabetes.

Keywords: islet transplantation, diabetes, vascularization, biomaterials, stem cells

\section{INTRODUCTION}

Diabetes is a complex metabolic disease in which the body's ability to produce or respond to insulin is impaired, resulting in hyperglycemia. To date, approximately 451 million people worldwide have diabetes, and the World Health Organization (WHO) projects this number to increase to 693 million by 2045 (1). The emergence and progression of both autoimmune-induced type 1 diabetes (T1D) and stress-induced type 2 diabetes (T2D) are affected by various genetic, metabolic, environmental, and immune factors. Nevertheless, the failure of islet $\beta$ cells mass or function is considered a predominant factor that impacts the pathology of diabetes. While, the pancreas is thought to be the main organ affected, both T1D and T2D and their associated complications involve multiple organs with heterogenous pathogenic mechanisms. Diabetes is attributed to defects in insulin secretion and action; disturbance in carbohydrate, fat, and protein metabolism; faulty micro- and macro- 
vascularization; chronic inflammatory state. All these pathologies result in complications, such as of blindness, retinopathy, nephropathy, neuropathy, and cardiovascular diseases (2-9). Emerging evidence suggests that diabetes is a risk factor for various other diseases, as illustrated by SARS-CoV-2 infection complications resulting from the direct infection in the endocrine and exocrine pancreas (10-30). The global burden of diabetes is steadily rising, affecting every nation and population. Strategies for mitigation, control, and treatment of diabetes have been the subject of intense research. Daily insulin injection therapy remains to be the standard care for patients with T1D, late-stage of T2D, and in some rare forms of diabetes (31). However, a daily insulin injection therapy, while lifesaving, does not exactly recapitulate the effectiveness of endogenous control of blood glucose by $\beta$ cells. In addition, the insulin injection therapy represents a chronic and costly burden for diabetic patients, and it does not entirely eliminate the risk of acute and chronic complications related to diabetes. Pancreatic islet transplantation, in which pancreatic islets are isolated from donors and percutaneously infused into the liver via the portal vein, is a current treatment for insulin-dependent diabetes (32-37). This procedure has been performed successfully on patients with T1D, providing exogenous insulin independence for several years. Additionally, pancreatic islet transplantation can be superior to daily insulin therapy in delaying diabetes-related complications and in exerting overall metabolic control $(34,37,38)$. Despite its efficacy, this allograft islet transplantation cannot be universally performed because of shortages in islet donors and side effects associated with the lifelong need for immunosuppression.

Recent advancements in the field of stem cells have brought us closer to addressing the shortage of cadaveric islets for use in transplantation. Various protocols utilizing human embryonic stem cells (hESCs) or human induced pluripotent stem cells (hiPSCs) have been developed to differentiate these cells into $\beta$ like cells with key markers for mature pancreatic islets (39-45) (31). These stem cell-derived $\beta$-like cells are capable of sensing blood glucose levels and are also capable of secreting various levels of insulin when transplanted into animal models of diabetes. Thus, these strategies can provide an alternative source for insulin-producing $\beta$-like cells derived from stem cells. Despite their therapeutic potential, the clinical viability of transplanting stem cell derived insulin-producing cells poses many challenges including the optimization of differentiation and maturation (46-48), graft rejection induced by one's immune system and long-term survival in vivo (49-52). Although, the current transplantation location used in clinical settings is through the hepatic portal vein in the liver, there is a growing consensus that the hepatic milieu may not be hospitable for functional islet transplantation and their long-term viability, not only for cadaveric human islets (53) but also stem cell derived islets. Therefore, it is important to improve the efficacy of islet transplantation by the development of biomaterials and transplantation sites which enhances graft survival for the future advances on islet therapy in diabetes.

In this review, we summarize current advances made on islet transplantation sites and how they affect graft rejection, immune response, and vessel formation.

\section{TRANSPLANTATION SITES}

The pancreatic islet transplantation procedure involves isolating pancreatic islets capable of secreting insulin from an autologous source, such as donors, or from the autonomous sources (a total pancreas resection caused by pancreatitis or similar injury). Pancreatic islets are released from the pancreas via a combination of chemical methods that involve collagenase and neutral protease digestion $(54,55)$ and mechanical methods $(56)$. Then, the islets are purified through variable centrifugations to separate islets from the pancreatic acinar and ductal tissue $(57,58)$. The isolated and purified pancreatic islets are then transplanted into the liver by percutaneous transhepatic islet transplantation at the portal vein sites. The liver is currently the preferred transplantation site because the procedure is minimally invasive with ease of access and has low rates of bleeding and thrombosis.

The liver can also provide oxygenation to the transplanted islets via the portal circulation until revascularization occurs. In addition, this approach allows insulin to be delivered to the liver and intestines. In 2000, Shapiro et al. reported the first proof of concept for pancreatic islet transplantation into the liver of seven T1D patients (35). A post hoc analysis of autologous islet transplantation study was reported that 173 pancreatectomized patients with autologous transplantation and 262 diabetes patients with allogeneic transplant showed that $85 \%$ of autologous transplant recipients and $66 \%$ of recipients of allogeneic transplant recipients were insulin-independent for two years after surgery (57).

Islet transplantation has proven to be successful in controlling hyperglycemia and providing insulin-independence for many diabetic patients. However, more research is needed to improve its success rate for long-term application. A key component in successfully optimizing islet graft survival after transplantation is the rapid establishment of blood flow for nutritional supply, oxygen supply, and immune regulation. It is estimated that approximately $50 \%$ of transplanted islets survive in the first few days of transplantation because of instant blood-mediated inflammatory reaction (IBMIR) and acute immune response (59, 60). Fewer transplanted islet survives thereafter because of the lack of vascularization for oxygen and nutritional supply (6163). This loss of freshly transplanted pancreatic islets requires the need for two or more donors for each recipient of pancreatic islets. In the long-term, transplanted pancreatic islets decline in function, possibly due to metabolic exhaustion or an inhospitable transplantation microenvironment. Additionally, graft rejection can occur because of the innate and adaptive immune response, which requires the need for life-long administration of immunosuppressants (64). It is still unclear how the transplantation site microenvironment affects the survival and functionality of transplanted pancreatic islets beyond the need for sufficient vasculature. While the liver is historically the preferred site, research indicates that the hepatic microenvironment is not as hospitable to transplanted pancreatic islets as was initially thought. Thus, researchers are investigating different transplantation sites to identify more hospitable and optimal locations for islet transplantation. In the following section, we summarize the 
different transplantation sites being explored for islet transplantation (Figure 1). Current advances on islet transplantation in these differential sites are also summarized (Table 1).

\section{Liver Transplantation Site}

The liver and portal vein have been identified as the preferred site for islet transplantation because of its ease of accessibility and associated low morbidity. This was evidenced by the fact that most of clinical islet transplantations have been performed at this site. A 1972 study in rats transplanted with syngeneic pancreatic islets into the kidney capsule with venous drainage shunted to the hepatic portal vein achieved complete reversal of hyperglycemia. This study established the importance of transplanting pancreatic islets close to the liver portal circulation to increase the concentration of insulin reaching the liver (109), suggesting that insulin delivery via the portal vein is more effective than intraperitoneal infusion. In 2006, Shapiro et al. (110) reported the results of a clinical trial using the Edmonton protocol, a highly improved allogeneic pancreatic islet transplantation protocol developed in 2000 (35). Seven diabetic patients were infused with over 4,000 islet [11,547 +/-1604 islet equivalent (IEQ)] per $\mathrm{kg}$ of recipient's body weight via the portal vein, with each recipient receiving the pancreatic islets from two to three brain-dead donors. Seven out of seven of these patients achieved insulin independence in their first year. In 2006, a multicenter clinical trial for pancreatic islet transplantation reported that 21 out of 36 patients achieved exogenous insulin independence for a year, and 16 patients were exogenous insulin independent for two years. The Edmonton protocol has become the foundation for many islet transplantation approaches (110). Improvements in both isolation protocol and standardization protocols now allows islet transplantation from donors to patients to be successfully performed within 72 hours. During the first few days after transplantation, the islets are only oxygenated only via diffusion in the low-oxygen tension portal vein. It takes approximately 7 to 14 days before the islet develops a functional vasculature (111),

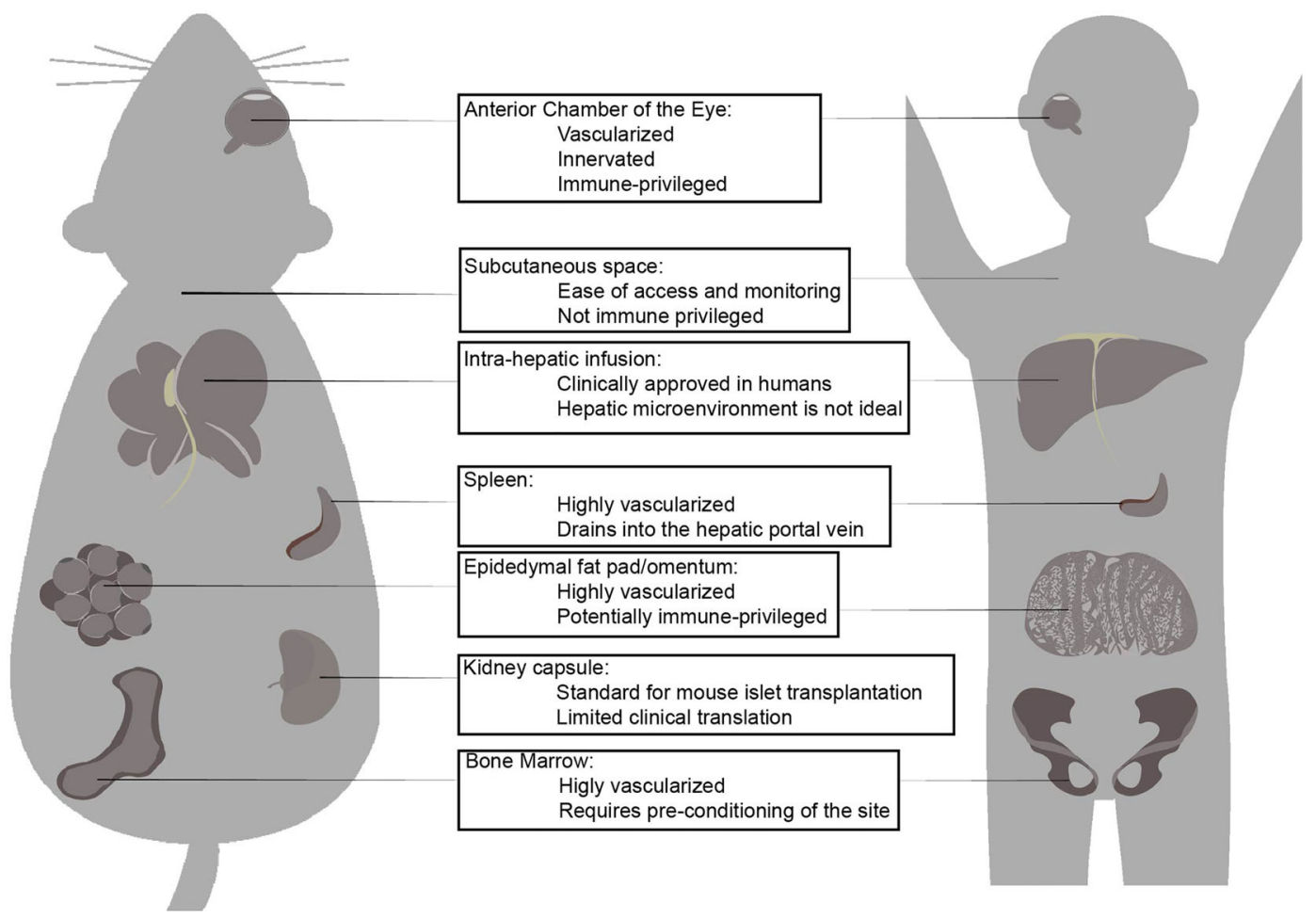

FIGURE 1 | Islet transplantation sites that have been tested in mouse models and higher mammalian models. The three major factors contribute to success of islet transplantation are the 1. Presence of vascularization and innervation, 2. Immune-modulating factors which affect innate inflammatory response and graft rejection, 3. Accessibility for surgical procedure and absence of major surgical complications. Each transplantation site shows advantages and disadvantages which have been explored. While intra-hepatic infusion is the only clinically applied site for islet transplantation, there are extra-hepatic candidate sites that may superior islet transplantation site. The anterior chamber of the eye is highly vascularized innervated and immune-privileged in most conditions low and atypical expression of $\mathrm{MHC}$ class I and II, as well as presence of anti-inflammatory and immune-modulating factors in the intra-ocular fluid is beneficial for islet engraftment. Subcutaneous space is not immune-privileged and poorly vascularized but ease of access and simplicity of surgical procedure and complications makes it an attractive site for islet transplantation. Liver via hepatic portal infusion is the only clinically approved site of transplantation due to success of Edmonton protocol, but extensive loss of islet necessitates for multiple islet donors. Hepatic micro-environment is considered a factor in long-term decline of viability of transplanted islets. Spleen is highly vascularized and drains into the hepatic portal vein and may contain immune-modulating Tregs. Omentum or epididymal fat (murine equivalent) is highly vascularized, and potentially-immune privileged. It can accommodate large islet volume, including a different immuno-modulating co-transplanted cells and biomaterials and devices. Kidney capsule is routinely used as site for islet transplantation in murine subjects, but clinical translation to humans is limited due to common diabetesrelated renal complications. Bone marrow is highly vascularized but requires pre-conditioning before it can be considered for islet transplantation. 
Anterior Islets from PdxCreER-

C57BL/6N albino mice

$\sim 300$ IEQ

Chamber of GCAMP in C57BL/6N

the Eye (ACE) background

Islets from C57BL/6 and

Streptozotocin-induced diabetic C57BL/6 mice and $129 \times 1$ mice Nude-Foxn1nu (nude) mice Islets from C57BL/6J and Streptozotocin-induced Tie2-GFP mice diabetic athymic male nude mice (B6;Cg/JBomtacFoxn1 ${ }^{\text {nu}} N 3$ )

Islets from C57BL/6 mice Streptozotocin-induced and NOD mice diabetic C57BL/6 mice; NOD-SCID mice given diabetogenic splenocytes

Mouse pseudo-islets from Streptozotocin-induced Ins1(Cre) knock-in in C57BL/6J background diabetic C57NL/6J mice

Mouse islets from 2 Streptozotocin-induced month-old and 18 month- C57BL/6 mice old C57Bᄂ/6 male mice; human islets from nondiabetic donors Allogeneic islets from

Allogeneic transplantation into baboon model of diabetes

Allogeneic islets from a healthy cynomolgus monkey

a Streptozotocin-induced diabetic baboon

Allogeneic transplantation into the T2D cynomolgus monkey

Streptozotocin-induced diabetic C57BL/6 mice

Autologous Islet transplantation in human
Four patients with islet infusion $\sim 300 \mathrm{IEQ}$

-150-200 IEQ

25-125 IEQ

-100 pseudo-islet approximately

200 IEQ

$\sim 18,000$ to 20,000 IEQ (approximately $2100 \mathrm{IEQ} / \mathrm{Kg})$

$\sim 12,000$ IEQ (1500

$\mathrm{IEQ} / \mathrm{Kg}$

$\sim 125-500$ IEQ

$\sim 32,000$ to 334,600 total IEQ per patient (666-4,780 IEQ)

\section{Development of a non-invasive in vivo}

fluorescence imaging of islets using the anterior chamber of the eye as a natural window

Study determining the involvement of cholinergic innervation in insulin secretion function of islets

Determination of the contribution of dono endothelial cells present from isolated islet in revascularization process

Evaluation and real-time visualization of how autoimmunity can occur during T1D

Proof of concept study of increasing transfection efficiency in beta islet by deaggregating beta islets and then transfecting with adeno-virus before allowing to re-aggregate into pseudo-islet before transplantation in anterior chamber of the eye

A study investigating the effect of agedependent impairment in islet function and vascularization.

Study evaluating feasibility of ACE as islet transplantation site in pre-clinical model of streptozotocin-induced diabetes

Evaluation of ACE as transplantation site for islet pre-clinical model of high-fat diet induced diabetes

Proof of concept study of transplanting islet into an easily accessible bone marrow

Pilot clinical study of testing feasibility and rmoglycemia observed at 2 weoks after transplantation, monitored for approximately over 200 days

Not available: metabolic effect on daily blood glucose change was not investigated

Normoglycemia reached in Median of 12.5 days (fresh islets) or median of 7 days (after 4-day cultured)

Normoglycemia reached in approximately 12 days, and observed until 47 days

Normoglycemia was achieved within two weeks in unreported percentage of mice, and maintained for approximately 40 days

Approximately $50 \%$ of diabetic recipient achieved normoglycemia within 50 days after transplantation, with majority maintaining glycemic control for up to 11 months

Exogenous insulin requirement decreased after 3

months, monitored until 357 days

Normoglycemia post-transplantation (88measurements); Observed for 348 days post-transplantation (POD $97-$ POD185; iridectomy POD186-POD348)

$52 \%$ of mice transplanted with 125 IEQ achieved normoglycemia within 85 days (median), and $76 \%$ of mice transplanted with $250 \mathrm{IE}$ achieved normoglycemia within 14 days (median)

safety of autologous human islet

transplantation into the patients' own bone 
Allogeneic human islet

Patients with T1D and

$\sim 287,000$ to

contraindication for intraportal $1,125,116$ total IEQ

islet infusion, and T1D $(2,727-10,684 \mathrm{IEQ}$

Islets from C57BL/6 or patients in randomized tria

BALB/c mice6

$$
\text { C57BL6 mice }
$$

Subcutaneous Landrace pig islets with pig bone marrow-derived mesenchymal stem cells (BMMSC), pig adipose derived mesenchymal stem cells (AMSC)
Syngeneic islets from C57BL/6 mice, or BAL mice, or human islets

Streptozotocin-induced diabetic C57BL/6 mice, and $\mathrm{Rag}^{-/ /}$mice

Human embryonic stem cell-derived pancreatic endoderm

Wistar rat islets and human islets

Streptozotocin-induced Rag $^{-/ /}$mice immune-suppressed Sprague-Dawley Rats Streptozotocin-induced
Streptozotocin-induced liabetic Wistar rats and cynomolgus monkeys $450 \mathrm{IEQ}$

125-300 IEQ/g for Wistar rat recipients, 15,000 to 62,500 $\mathrm{IEQ} / \mathrm{Kg}$ for primate recipients transplant), 2000

human islet IEQ in immunodeficient $\sim 500$ IEQ (syngeneic

Feasibility study and pilot randomized tria

of patients with T1D to study safety and

outcome of allogeneic islet transplantation into the bone marrow

Study that evaluated bone-marrow Normoglycemia reached within 1 week post-

precondition via local irradiation to improve transplantation and monitored for up to 6 weeks postsyngeneic and allogeneic transplantation in transplantation mice

Porcine islets and mesenchymal stem cells For islets alone, mean weeks of normoglycemia is 28 from bone marrow and adipose tissue, co- weeks, while Islets with adipose-derived MSC and bone encapsulated in P.E. alginate coated,

collagen matrix device were transplanted subcutaneously in Wistar rats and cynomolgus monkeys to determine if this system could improve vascularization,

implant oxygenation, and metabolic control in short term and long term.

The subcutaneous space was pre-treated with medically-approved nylon or silicone catheter for one month before being

removed (device-less). One month implantation was enough to induce a subcutaneous space with local neovascularization without formation of thick, mature fibrotic scar, before being transplantation with islet

$0.5-1.0 \times 10^{7}$ cells diabetic, immunodeficient B6/

Use of similar "device-less" technique of implanting nylon catheter in subcutaneous space for month before removal. Subsequent implantation of human embryonic stem cell-derived pancreatic endoderm for in vivo maturation

Islets were embedded in submillimeter collagen cylinders, coated with endothelia cells before being transplanted subcutaneously.

diabetic SCID/beige mice and

$-750 \mathrm{IEQ}$ diabetic C57BL/6 and NOD/ SCID mice

100-400 mouse IEQ Transplantation into a specific subcutaneous space in the inguinal subcutaneous white adipose tissue allowed approximately 60 days, compared to one out of five/six for neovascularization and connection with of mice receiving either anti-CD40L or CTLA4lg only. feeding vessels from the inferior epigastric Normoglycemia was maintained for a duration of artery and vein.
Of the mice that were transplanted at epididymal fat and un-treated subcutaneous space, only 33\% achieved normoglycemia. For mice that were transplanted in 'device-less' subcutaneous space, 100\% achieved normoglycemia for an average of $99.8 \pm 3.8$ days

five out of six diabetic rats have restored normoglycemia within 10 days for 21 days

Six out of eight diabetic mice receiving both CTLA4 Ig and anti-CD4OL antibody regained normoglycemia within

approximately 120 days after which the graft was removed 
F344 rat islet, Porcine

SCID mice, total-

islets

pancreatectomized pig as model for T1D

Sprague-Dawley rat islets

diabetic athymic BALB/cnude mice

Murine, porcine and human islets and cynomolgus islets (autotransplantation)

Streptozotocin-induced B6/SCID and Balb/c/nude wild-type B6 mice (with immune-suppressive regimen), as well as $90 \%$ pancreatectomized cynomolgus monkey Pseudo-islets from de- Streptozotocin-induced aggregated rat or human diabetic SCID/bg mice islets cells

C57BL/6 and BALB/C mouse islets, SpragueDawley rat islets, human islets, HUES8 stem-cel derived $\beta$ cell clusters.

Streptozotocin-induced beagle dogs

Sprague-Dawley male rats Streptozotocin-induced and female Gö;ttingen minipigs

Omentum Syngeneic C57BL/6J female mouse islets

Streptozotocin-induced NOD-SCID male mice

\section{1,000-2,000 rat} islets; approximately sheet seeded with islet was transplanted 7,007 to $10,005 \mathrm{IEQ} /$ subcutaneously in SCID mice and total$\mathrm{Kg}$ of porcine islets pancreatectomized pigs

was used for porcine

recipients

$\sim 4,000$ rat IEQ and $\sim 8,000$ human IEQ

Esterified collagen scaffold functionalized with heparin contained varying number human adipose-derived stem cells and islets, transplanted subcutaneously diabetic immune-incompetent mice and immune-competent diabetic male C57BL/6, male SCID-beige mice, and male NOD/NSG mice and healthy diabetic male C57BL/6 mice diabetic C57BL/J6 male mice and streptozotocin-induced

\section{$\sim 400-800$ murine $\quad P$ anc}

Pancreatic islets were transplanted

IEQ; 250-500 porcine subcutaneously with a viability matrix IEQ; 400 human IEQ containing collagen, L-glutamine, FBS, affected long-term functionality of engra islets

$1.5 \times 10^{6}$ islet cells (dose equivalent of approximately 750 IEQ

Collagen gel scaffold embedded with the different cell types of the pancreatic islet for uniform pseudo-islet size, cell composition and proportion

600-700 IEQ 1700 Use of medical-grade, siliconehuman islet clusters, polycarbonate-urethane biomaterial $\sim 2500$ HUES8 stem- encapsulating an alginate core containing cell derived $\beta$ cell clusters rodent islets, or human islets or HUES8 stem-cell derived $\beta$ cell clusters to assess foreign body reaction, immune-protective function, and normoglycemia function

500 rat IEQ; 1500 rat Proof of concept study using an inverse breathing encapsulation device (BED) that supplies oxygen to transplanted islet via gas-solid reaction between $\mathrm{LiO}_{2}$ and cellular metabolism bi-product $\mathrm{CO}_{2}$.

600 mouse IEQ

Study comparing three leading extrahepatic islet transplantation site (subcutaneous, small bowel mesentery, epididymal fat pad) for synthetic vasculogenic hydrogel-based islet transplantation pseudo-islets with modifiable proportion either syngeneic, allogeneic, or xenogeneic
$100 \%$ of SCID mice transplanted with four islet-MSC

sheet achieved normoglycemia within 1 week, and maintained normoglycemia for 84 days; normoglycemia was achieved in one week, and maintained until second week during which graftectomy was performed

Higher number of human adipose-derived stem cells resulted in normoglycemia within 1 day posttransplantation, and maintained for up to 100 days

Normoglycemia was achieved within 24 hours posttransplantation with graft survival and maintained for up and to 127 days (immune-incompetent mice) and up to 529 days (wild-type mice under immune-suppressive

regimen); T1D cynomolgus monkey (auto-transplantation) maintained normoglycemia until 820 days posttransplantation.

Six out of nine SCID/B6 mice transplanted with pseudoadMSC returned to normoglycemia in approximately 10 days until day 21 , during which graftectomy was performed

Syngeneic mouse model achieved normoglycemia within one week for 120 days (13 out of 17 mice), while normoglycemia was achieved within one week for up to 100 days in immune-deficient mouse model (8 out of 11 mice). In immune-competent mice, normoglycemia was achieved within a week for up to 8 weeks (10 out of 16 mice)

Improved iBED version resulted to eight out of ten C57BL/6 mice achieving normoglycemia for approximately 92 days, with better glucose metabolism even after 90 days. Non-fasting blood glucose level was not reported in minipigs, but retrieved device exhibited more surviving islets than controls after 1 and 2 months of implantation

The islets with the vasculogenic hydrogel transplanted into the epididymal fat pad achieved normoglycemia within two weeks, for more than 35 days up to 100 days (approximately $75 \%$ of recipients) 


\begin{tabular}{|c|c|c|c|c|c|c|}
\hline $\begin{array}{l}\text { Alternative } \\
\text { Site }\end{array}$ & Islet Used & Recipient Species & $\begin{array}{l}\text { Number of Islets } \\
\text { per recipient }\end{array}$ & Description & Results & Reference \\
\hline & Lewis male rat islet & Lewis female rats & $\sim 10,000 \mathrm{IEQ} / \mathrm{Kg}$ & $\begin{array}{l}\text { Non-biodegradable knitted polymer mesh } \\
\text { inserted into the omentum with } \\
\text { subcutaneous access for } 4 \text { weeks before } \\
\text { islets are introduced. Insulin pellets were } \\
\text { also introduced into the Lewis rat } \\
\text { recipients }\end{array}$ & $\begin{array}{l}\text { All ten rat islet recipients achieved blood glucose of } \\
8 \mathrm{mmol} / \mathrm{L} \text { as a result of combined insulin pellet and } \\
\text { transplanted islet, and maintained for up to } 100 \text { days }\end{array}$ & (90) \\
\hline & $\begin{array}{l}\text { Wistar Furth male rat } \\
\text { islets, Cynomolgus } \\
\text { monkeys }\end{array}$ & $\begin{array}{l}\text { Streptozotocin-induced } \\
\text { diabetic female Lewis rats, } \\
\text { Streptozotocin-induced } \\
\text { diabetic cynomolgus } \\
\text { monkeys }\end{array}$ & $\begin{array}{l}17,338 \pm 881 \mathrm{IEQ} / \mathrm{Kg} \\
\text { for syngeneic rat } \\
\text { model; } 3000 \mathrm{IEQ} \text { of } \\
\text { allogeneic rat model; } \\
\text { Cynomolgus monkey } \\
\text { islet of approximately } \\
48,700 \mathrm{IEQ}(9347 \\
\text { cynomolgus monkey } \\
\mathrm{IEQ} / \mathrm{Kg} \text { ) }\end{array}$ & $\begin{array}{l}\text { Islet transplantation into the omentum } \\
\text { utilizing a biological, resorbable plasma- } \\
\text { thrombin scaffold to monitor metabolic } \\
\text { improvement in diabetic rats, as well as } \\
\text { cytoarchitecture of transplanted islets }\end{array}$ & $\begin{array}{l}\text { Seven out of seven syngeneis rats achieved } \\
\text { normoglycemia within } 2 \text { days and maintained } \\
\text { normoglycemia for more than } 200 \text { days. Four out of four } \\
\text { immune-suppressed allogeneic rats achieved } \\
\text { normoglycemia five days post-transplantation, and } \\
\text { maintained for more than five weeks. }\end{array}$ & (91) \\
\hline & $\begin{array}{l}\text { Cynomolgus monkey } \\
\text { islets }\end{array}$ & $\begin{array}{l}\text { Non-diabetic cynomolgus } \\
\text { monkeys; Streptozotocin- } \\
\text { induced diabetic C57BL/6 } \\
\text { mice }\end{array}$ & $\begin{array}{l}\text { Approximately } 1500 \\
\text { cynomolgus monkey } \\
\text { islet in intraperitoneal } \\
\text { space of diabetic } \\
\text { C57BL/6 mice; } \\
\text { approximately } 5000 \\
\text { cynomolgus monkey } \\
\text { islets were seeded in } \\
5 \mathrm{~mL} \text { of alginate } \\
\text { formulation at } \\
\text { seeding density of } \\
1000 \text { islets per } \mathrm{mL} \text { of } \\
\text { alginate formulation }\end{array}$ & $\begin{array}{l}\text { Study investigating foreign body response } \\
\text { to different immune-modulating formulation } \\
\text { of alginate in islet encapsulation method, } \\
\text { as tested and transplanted in non-diabetic } \\
\text { non-human primates. Islet viability is } \\
\text { measured after } 1 \text { month and } 4 \text { months of } \\
\text { transplantation into the omental bursa. }\end{array}$ & $\begin{array}{l}\text { Alginate formulation SLG20 allowed for normoglycemia in } \\
\text { diabetic C57BL/6 mice for approximately } 120 \text { days } \\
\text { without the need for immunosuppressant. Marginal } \\
\text { fibrosis was observed after } 1 \text { month of transplantation in } \\
\text { these C57BL/6 mice. The same results were not } \\
\text { recapitulated when the same formulation was tested in } \\
\text { cynomolgus monkeys; Instead, a different alginate } \\
\text { formulation, Z1-Y15, showed reduced foreign body } \\
\text { response in the form of fibrosis when tested in non- } \\
\text { human primates. Six out of seven encapsulated islets } \\
\text { showed higher viability after retrieval from transplantation. } \\
\text { Blood glucose control was not investigated in these non- } \\
\text { human primates. }\end{array}$ & (92) \\
\hline \multirow[t]{4}{*}{ Spleen } & $\begin{array}{l}\text { Islets from } \\
\text { Pancreatectomized } \\
\text { Mongrel dogs }\end{array}$ & $\begin{array}{l}\text { Autotransplantation } \\
\text { Pancreatectomized non- } \\
\text { diabetic Mongrel dogs }\end{array}$ & $\begin{array}{l}\text { Approximately } 9000- \\
13,000 \text { IEQ per } \\
\text { recipient }\end{array}$ & $\begin{array}{l}\text { Comparative study of omental pouch vs } \\
\text { splenic site for islet transplantation with } \\
\text { focus on hypoglycemic correctional } \\
\text { response in these animals }\end{array}$ & $\begin{array}{l}\text { Time to normoglycemia was not indicated but beta islet } \\
\text { response to insulin-induced hypoglycemia was deemed } \\
\text { normal while alpha cell response was not. The response } \\
\text { in omentum and splenic transplantation were similar }\end{array}$ & (93) \\
\hline & $\begin{array}{l}\text { Syngenetic islets from } \\
\text { C57BL/6 }\end{array}$ & $\begin{array}{l}\text { Streptozotocin-induced } \\
\text { diabetic C57BL/6 mice } \\
\text { (Syngeneic) }\end{array}$ & $\begin{array}{l}\text { Approximately } 50- \\
200 \text { IEQ per recipient }\end{array}$ & $\begin{array}{l}\text { Comparative study of hepatic portal vein, } \\
\text { kidney capsule and spleen as islet } \\
\text { transplantation site }\end{array}$ & $\begin{array}{l}\text { Spleen has the lowest number of islets required to } \\
\text { achieve normoglycemia, compared to portal vein or } \\
\text { kidney with reduced inflammation and potential } \\
\text { expansion of islet graft. }\end{array}$ & (94) \\
\hline & $\begin{array}{l}\text { Porcine Islets from fetal } \\
\text { pigs }\end{array}$ & $\begin{array}{l}\text { Adult pancreatectomized } \\
\text { Westran pigs }\end{array}$ & $\begin{array}{l}\text { Approximately more } \\
\text { than } 5000 \text { IEQ per } \\
\text { recipient }\end{array}$ & $\begin{array}{l}\text { Comparative study of kidney capsule, } \\
\text { hepatic portal vein and spleen as islet } \\
\text { transplantation site }\end{array}$ & $\begin{array}{l}\text { Normoglycemia was achieved by day } 120 \text { post- } \\
\text { transplantation. Glucose metabolism is better in kidney } \\
\text { than liver and spleen. }\end{array}$ & (95) \\
\hline & $\begin{array}{l}\text { Human islets or C57BL/6 } \\
\text { murine islets }\end{array}$ & $\begin{array}{l}\text { Alloxan-induced diabetic } \\
\text { C57BL6 mice (syngeneic) or } \\
\text { RAG-1 or SCID } \\
\text { immunodeficient mice } \\
\text { (recipient for human islets) }\end{array}$ & $\begin{array}{l}\text { Approximately } 2000 \\
\text { IEQ per recipient }\end{array}$ & $\begin{array}{l}\text { Comparative study of Portal vein, } \\
\text { Quadricep muscles, kidney capsule, liver } \\
\text { capsule, and splenic capsule as islet } \\
\text { transplantation site }\end{array}$ & $\begin{array}{l}\text { Spleen and liver capsule were inferior compared to other } \\
\text { transplantation site. Skeletal muscle and portal vein } \\
\text { should similar engraftment efficiency while kidney capsule } \\
\text { performed yielded the best outcome at } 75 \% \text { and } 100 \% \\
\text { success rate for human and murine islet transplantation }\end{array}$ & (96) \\
\hline
\end{tabular}


Syngeneic islets from C57BL/6 mice

Streptozotocin-induced diabetic C57BL/6 mice

Approximately 300 EQ per recipient (syngeneic)

Intramuscular Porcine islets from Lardrace large white pigs (Papio anubis)

Human islet

7-year old patient (autotransplantation)

Syngeneic islets from male Lewis rats diabetic Lewis Rats (syngeneic)

Syngeneic islets from Lewis rats

Streptozotocin-induced diabetic Lewis rats (syngeneic)

Syngeneic islets from C57BL/6 mice

Streptozotocin-induced diabetic C57BL/6 mice

Islets from minipigs

Pancreatectomized minipigs (Non-syngeneic)

Neonatal Porcine Islets from 2-5 day old hybrid German landrace piglets

Streptozotocin-induced diabetic NOD-SCID IL2ry-/(NSG) mice

Islets from Balb/c mice

Streptozotocin-induced diabetic Balb/c mice recipient

Approximately

10,000 IEQ/Kg per recipient

Approximately

163,000 IEQ $(6400$ $\mathrm{IEQ} / \mathrm{Kg}$ )

Approximately 2400 IEQ per recipient

proximately 1500 2000 IEQ per

recipient

transplantation sites, determining marginal mass required and mean time to achieve normoglycemia in murine models of islet transplantation

Approximately 1000 Transplantation study into the gracilius $\mathrm{IEQ} / \mathrm{Kg}$ per recipient muscle in minipig models to determine the best surgical technique to allow for islet engraftment into the muscles

Approximately 2500- Comparison of kidney capsule vs lower

3000 neonatal

porcine islet-like clusters

hind-limb muscle as transplantation site for xenogeneic transplantation murine models

Approximately 100$500 \mathrm{IEQ}$
Comparative study of hepatic sinus tract vs Spleen performed better than hepatic sinus tract as islet

Normoglycemia was achieved within 24 hours posttransplantation, and the different immunosuppressive regimens allowed for porcine islets to survive beyond 14 days in non-human primate recipients.

Observational period lasted for two years, and the patien achieved better quality of life but insulin-independence was not achieved

Islet engraftment was better in bio-compatible scaffold pre-treated rats, with 2-4 times increase in vascularization after 60 days of observation. Normoglycemia was achieved in this cohort I less than 10 days and maintained for up to 60 days Normoglycemia was achieved in less than 20 days and maintained for more than 100 days. It was determined that there is volume-dependent increase in muscle inflammatory response and peri-islet fibrosis. Pearl-onstring transplantation technique allowed for better islet engraftment into the muscle

Kidney required the least number of islets required to achieve normoglycemia followed by omentum and last, liver and muscle. Transplantation in muscle took the longest to achieve normoglycemia compared to other transplantation sites

Despite minimizing damage to the muscle during

transplantation procedure to minimize immune response, islets transplanted into the muscle did not perform better than islets transplanted into the hepatic portal vein. Neonatal porcine islet-like clusters needed an in vivo maturation period; therefore normoglycemia was achieved after more than 50 days in $50 \%$ of the animals transplanted in kidney or muscle. Transplantation into the kidney capsule achieved normoglycemia faster than muscle

Comparative study to determine the effects Islet imbedding into Matrigel improved engraftment of transplanting islet with Matrigel on efficiency into the muscle. The difference in the amount of growth difference in engraftment efficiency after day 7 posttransplantation. The proportion of mice achieving normoglycemia following intramuscular transplantation with islets and Matrigel was equal to or greater than mice receiving intraportal transplanted islets 
but even then, the transplanted islets chronically maintain a low endogenous oxygen tension compared to native islets (112). As such, transplanted islets suffer hypoxic insults, which contributes to the failure in islet survival $(113,114)$. Pre-treatment of islets with anti-hypoxic agents before transplantation shows promise in improvement of the islet survive in the short term, but the need for extensive vascularization is still a major issue for the long-term islet survival. Alternative transplantation sites that are pre-existing, or capable of developing extensive vascularization leading to similar nutritional and oxygen supply to the native islets are actively being investigated. Strategies to promote angiogenesis early after transplantation via angiogenic biomaterials and factors are also being explored. When islets are transplanted via the portal vein, they spontaneously settle into the peripheral branches. This produce risk of portal vein thrombosis and other vascular complications, such as variceal bleeding, intravascular coagulation, and intraperitoneal hemorrhage. While the risk for complete thrombosis is rare, partial thrombosis can occur more frequently and affect the function of both transplanted islets and liver, leading to partial liver damage and necrosis (115). Thrombosis also induces an inflammatory response that is detrimental to long term islet survival. Additionally, it can cause instant blood-mediated immune responses and activate the complement and coagulation cascades, leading to macroscopic clots that can further interrupt blood flow and exacerbate hypoxic insults to the transplanted islets and liver.

Immune responses are exaggerated by MHC mismatch meaning that the source of pancreatic islets have a great impact on both short and long-term islet viability and functionality. If the source of islet transplant is from MHC mismatched another individual or donors, it may require for the use of immune-suppressive regimen in order to delay or avoid graft rejection and extend the long-term viability of transplanted islets. In addition, even though the transplanted islets are generated from patients' own iPSCs (Thus MHC matching), long-term immune suppression may be still required due to autoimmune reaction against insulin in T1D patients who are already presented insulin as an antigen. However, some of these immunosuppressive drugs can be toxic to transplanted islets as they are located in the hepatic portal vein, which exposes them to the immunosuppressive drugs near serum levels. Extensive research is now focusing on identifying less toxic immunosuppressive regimens, as well as optimal sites that would not expose the transplanted islets to high concentrations of immunosuppressive drugs. There are also indications that even in the absence of immunosuppressive drugs, the function and viability of transplanted islets decline (116). The exact mechanism that mediates this decline is currently unknown, and direct observation and evaluation of the transplanted islet is often very difficult because of the location of the transplanted islets.

IBMIR is a major factor contributing to the initial loss of islets after transplantation, and strategies are being explored to prevent or mitigate the damage caused by this inflammatory reaction. One particular strategy is focused on the use of low-molecularweight heparin, which has been shown to decrease IBMIR in many in vitro and in vivo animal models (53). Other potential strategies include thrombin inhibitors, complement inhibitors, as 
well as other anti-inflammatory tissues such as human adiposederived mesenchymal stem cells (hADSCs) (117). It has been shown that the co-transplantation of islets with hADSCs or factors secreted by hADSCs can ameliorate the immune response against transplanted islets $(82,118)$, however, only heparin is currently used in clinical settings (119). Once the islets settle into the peripheral veins, it is difficult to monitor the islets for functionality and potential damage. Successful islet transplantation is often monitored indirectly, via c-peptide and insulin production, whereas IBMIR is based on the measurement of thrombin-antithrombin complex levels. The reported decline in the function of transplanted islets, even in the absence of cytotoxic immunosuppressants is very difficult to monitor because of the nature of the transplantation sites, in which direct visualization is too invasive, and current technology for visualization cannot properly gauge the health and functionality of the engrafted islets. The proximity of the liver to the gastrointestinal tract also indicates that liver-transplanted islets are exposed to toxins, antigens, and metabolic products from the gastrointestinal tract and its resident microbiota. As such, changes in gut microbiota and gut barrier integrity can contribute to the functionality and survival of transplanted islets (53). Microbiota diversity and gut function are altered in T1D patients (120-122). The effects of a pre-existing diabetes-linked microbiome have not been explored in islet transplantation, but these are the factors that must be considered when assessing the survivability and functionality of transplanted islets.

All of these liver-associated factors that contribute to the decline of transplanted islets highlight the need for an extrahepatic site for islet transplantation that would be less toxic to the transplanted islets. Alternative transplantation sites and techniques that would allow for rapid observation and evaluation of the transplantation are needed.

\section{Anterior Eye Chamber Transplantation Site}

The anterior chamber of the eye (ACE) has been gaining considerable interest as an alternative site for islet transplantation because of its accessibility, highly vascularized oxygen supply, and immune-privileged character. A previous study demonstrated that in mouse and non-human primate models of T1D, intraocular islet transplantation showed superior efficacy and immune modulation that improved hyperglycemia more in the long-term than that of the liver transplantation site. Although clinical trials in humans are currently planned for patients with T1D who are legally blind in the eye where the islet is to be transplanted, it is not known how the graft islets in the ACE affect vision and related neural systems. This may limit the opportunity for intraocular islet transplantation in non-blind T1D patients. Nevertheless, this transplantation method is also beneficial for the non-invasive monitoring of graft survival. It has been demonstrated that the ACE allows for adequate engraftment of tissues from the heart, muscles, pituitary gland, liver and prostate (123-125). The dense vascularization of the iris allows for rapid angiogenesis of transplanted tissue contributing to the successful engraftment and survival of the graft (126). This site also offers the advantage of the graft being visualized non-invasively through the see-through cornea. The same advantages of ease of access, vascularization, innervation, and immune privilege also apply for pancreatic islet transplantation into the ACE.

Pancreatic islet transplantation into the ACE has been tested in rodents and non-human primates (NHP). The ease of access and straightforward surgical procedure allows relatively simple transplantation for monitoring of pancreatic islet's functionalitycoupled morphology in single islets or single-cell resolution (126, 127). In brief, the islets are carefully introduced to the cornea near the sclera through a small perforation, avoiding damage to the iris and bleeding. After which islets are allowed to settle into the cornea for approximately half an hour to facilitate attachment to the iris (127). The high vascularization density in the eye allows for rapid vascularization of transplanted islet. In mice, angiogenesis can be observed in as little as 24 hours (128), whereas complete vascularization is observed within four weeks at the same vascular density compared to native islets (127). Revascularization begins with the appearance of a large blood vessel followed by progressively smaller capillaries (70). The newly formed capillary network originates from a combination of endothelial cells within the transplanted islets as well as endothelial cells from the iris (67). Even in the absence of endothelial cells from the pseudo-islet or islet, vascularization can still occur with adequate fenestration that allows for the exchange of nutrients similar to that of native islets $(67,69)$.

The ACE also allows for reinnervation of the transplanted islets. Dense innervation in the eye contributes to the sympathetic and parasympathetic innervation of transplanted islets (124), which is important for the modulation of insulin release (129). Reinnervation starts at third days and plateaus at three months with an innervation pattern similar to that of native islets (66). As such, ACE engraftment has also been used to study innervation. It is important to note that the nerves innervating islets are probably not connected to the hypothalamic region but to a different central autonomic nervous circuitry compared to the native islets, affecting islet function modulation and not control (66). More research is needed to delineate the different effects of neuronal circuitry and their primary and secondary effects on glucose homeostasis (130). One major advantage of ACE transplantation is the relatively low number of islets required for complete control of hyperglycemia. In rodents, approximately 125 islets are sufficient to completely reverse diabetic symptoms and achieve normoglycemia, and only 50 islets are required to increase survival of rodent models of T2D $(68,126)$. Transplantation into the kidney capsule, a site often used as a control for islet transplantation in rodent, requires approximately 250 IEQ, which is double the number required to produce the same effect in the ACE (68). These remarkable effects have been attributed to increased and rapid vascularization and innervation. This reduced number of islets required to alleviate hyperglycemia is a major advantage of ACE transplantations that circumvent the limitations of shortage of islets and donors. Another contributing factor to the utility of the ACE for islet transplantation is the status of sites as immune-privileged at certain conditions, even allowing for immune-tolerance.

The ACE microenvironment is rich in immunosuppressive molecules that influence the activity of immune cells and the presentation of antigens. This phenomenon is termed as anterior 
chamber-associated immune deviation (ACAID), in which the aqueous microenvironment inhibits $\mathrm{T}$-cell proliferation in mixed lymphocyte reactions and T-cell proliferation $(131,132)$ suppresses IFN $\gamma$ production and promotes TGF $\beta$ (133). Immune-modulatory factors have also been identified in the ACE. These factors include $\alpha \mathrm{MSH}$ and CGRP along with TGF $\beta$, which suppresses the activation of inflammatory macrophages (134, 135); the MIF protein that prevents NK-cell activation, and the FasL protein that suppress activation of Th1 $\mathrm{T}$ cells and also regulates neutrophil and macrophage activation (136). There is also atypical and lower expression of MHC class I molecules and no expression of MHC class II molecules in corneal epithelial tissues is observed (137-139). Certain $\mathrm{T}$ cells are also inhibited and transformed from IFN $\gamma$-producing $\mathrm{T}$ cells to TGF $\beta$-producing regulatory $\mathrm{T}$ cells.

The immune-modulating molecules in the ACE environment establish a barrier that maintains the induction of inflammation under control, even during transplantation. It is important to note that this immune-privileged status of the ACE is achieved only in the absence of a lymphatic bridge form connecting the ACE to the lymphatic system. Transplanted islets expressing MHC class II proteins as well as damage from surgical procedures can induce an immune response compromising the immunotolerant environment of the ACE $(68,135)$. Because of this, the ACE can be used to monitor auto-immune response in islet cells, while simultaneously monitoring the morphology of transplanted islet. A study by Tun et al. demonstrated that total of 12,000 islets (1500 IEQ $/ \mathrm{kg}$ ) transplantation in a left eye site in cynomolgus monkeys induced with early T2D through a high fat diet was able to delay progression of T2D and related complications (72). The authors observed that three months after immunosuppressants were withdrawn, the primates were still able to control hyperglycemia, indicating an acquired immune privilege/tolerant status for the transplanted islets. A similar study in 2011 by Perez et al. employed islet transplantation into the ACE of baboons using 20,000 IEQ (71). In both baboons and cynomolgus monkeys, glucose control was achieved with the transplanted islets without any clinically significant damage to the vision. However, innervation of islets in the eye may not be connected to the hypothalamic region of the brain, which controls glucose homeostasis. In addition, light has a potentiating effect on islets, potentially affecting insulin secretion and control (66). Finally, transplantation in the eye may result in the formation of cataracts, and collagen deposition into the eye blood vessels $(70,140)$. Anterior chamber of the eye is promising islet transplantation site, as demonstrated in different animal models including non-human primates but there are hesitations to its clinical applicability especially with the eye being a very sensitive and important organ. Transplantation into the anterior chamber of the eye demonstrated minimal islet required to achieve normoglycemia, coupled with robust vascularization and innervation post-transplantation, followed by immune-privileged microenvironment with the possibility of immune-tolerance being achieved. These are the ideal conditions for an islet transplantation site, but whether the same conditions can be achieved in humans is yet to be determined. Possible side effects such as cataract formation also need to be investigated. There are currently two recruiting clinical studies utilizing anterior chamber of the eye as islet transplantation site (NCT02916680 and NCT02846571). NCT02846571 is a pilot study aiming to transplant islet into severely visually impaired diabetic human eye to determine the safety of the procedure while NCT02916680 aims to determine the safety and efficacy of the procedure in healthy anterior chamber of the eye. These clinical studies would elucidate the applicability of the islet transplantation in the anterior chamber of the eye and whether the impressive results in animal models can be recapitulated in human patients.

\section{Bone Marrow Transplantation Site}

Bone marrow is an alternative candidate for pancreatic islet transplantation because of its specific microenvironment. The bone marrow is an ideal site for islet transplantation because it is well-protected from external shocks, extravascular and wellvascularized. The presence of extensive vascularization without direct contact with blood, is essential for its functionality and viability. The broad distribution of bone marrow and ease of access allow multiple transplantations at different sites, overcoming the aforementioned size and amount limits. These limits impede hepatic portal vein transplantation due to constrains in portal vein pressure, and other similar technical and surgical restriction. Bone marrow transplantation is also a potentially less invasive procedure, with low risk and easy access for sampling via bone aspiration biopsy. However, a possible ramification of bone marrow transplantation is that hyperinsulinemia has the potential to contribute to hyperproliferative diseases such as bone marrow cancer development through the growth-promoting effects of elevated insulin. Yet this risk is also present in intraportal infusion as observed in some diabetic rats that received intraportal islet infusion and had an increased incidence of adenomas and hepatocellular carcinoma (141, 142).

In 2009, Cantarelli et al. used syngeneic mouse models for pancreatic islet transplantation into the bone marrow. In their model, the transplanted islets survived for more than a year without compromising hematopoietic activity with better metabolic parameters (73). The percentage of mice achieving normoglycemia and the timing were superior in bone marrow compared to intrahepatic infusion using the minimal mass model. Simultaneously, the quality of glucose metabolism in bone marrow was similar to that of intraportal infusion. The morphology and cellular composition of the bone marrow-transplanted islets showed significant changes, including increased size and a more compact morphology, which was attributed to the isolation and preparation method. The ratio of islet alpha cells to the beta cells in bone marrow transplant was also similar to islet control, whereas this ratio was decreased in intraportal infusion which is a possible explanation for the deficient glucagon response observed in many intrahepatic portal vein transplant patients.

As proof of concept, Cantarelli et al. performed autologous pancreatic islet transplantation into the iliac crest bone marrows of four human patients that had contraindication for intraportal infusion. This was the first report of successful endocrine tissue engraftment in the bone marrow (74). These patients underwent total pancreatectomy, and islet engraftment was successful based on 
the circulating c-peptide levels after islet transplantation into the bone marrow. All four patients required exogenous insulin treatment but maintained good glycemic control with sustained endogenous insulin production. Red and white blood cell levels and platelet counts were unaffected by the presence of islets in bone marrow and were within the normal, expected values. Bone marrow biopsies displayed the presence of all four types of pancreatic islet cells (insulin, glucagon, somatostatin, and pancreatic polypeptide) one year after transplantation as evidenced through histological staining and the quantitative PCR for mRNA markers of normal pancreatic development, function, and differentiation. The presence of CD34+ endothelial cells was indicative of islet neovascularization. Their report indicated that islet transplantation into the bone marrow was a safe and reproducible approach, with the bone microenvironment able to support islet revascularization and function. Their biopsy also indicated that transplanted islets can be monitored through a simple aspirate biopsy procedure because the bone marrow is enclosed. This is a major advantage over intraportal infusion, in which islet normally engrafts randomly in the hepatic portal vein capillary tree making it harder to monitor. However, this success in islet auto-transplantation into the bone marrow was not reinforced when the same researchers performed islet allotransplantation into the bone marrow of T1D patients. Their pilot randomized trial in 2019 with T1D patients showed graft loss in most of the patients within four months, independently of the induction agent or presence of maintenance immunosuppression. From their biopsies and antibody responses, the authors concluded that this rejection was a result of the autoimmunity recurrence and that this rapid rejection of pancreatic islet graft in the bone marrow may be caused in closer proximity to bone marrow tissue-resident mature CD4+ and CD8+ T cells. Furthermore, the bone marrow microenvironment post-transplantation of islets may contribute to the expansion of autoreactive T cells, such elevated concentrations of IL-7, or the low oxygen tension in the bone marrow despite very high vascular density. Finally, the authors concluded that the success seen in the pre-clinical and NHP models of T1D is difficult to replicate in humans without creating models of autoimmune-mediated rejection of pancreatic beta islets (75). Bone marrow as a transplantation site may not be ideal for pancreatic islet without first preconditioning the local bone marrow microenvironment for immune-modulation or cytoprotection with localized bone marrow irradiation (76)

\section{Subcutaneous Space Transplantation Site}

Subcutaneous transplantation is a very attractive alternative site for islet transplantation, due to simplicity of the surgical procedure, unlikelihood of surgical complications, ease of access for graft monitoring, and possible retrieval of the transplant. However, the relative avascular nature of the subcutaneous space, and therefore lack of access to nutrients and oxygen hampers the utility of this transplantation site. As such, subcutaneous transplantations often requires the use of bioengineering devices and biomaterials, drug and trophic factors delivery systems and strategies to induce early angiogenesis, without which transplanted islets would not engraft sufficiently to achieve normoglycemia (143). There are various strategies in engineering biocompatible biomaterials that would induce vascularization and contribute to the survival and engraftment of transplanted islets. Numerous technologies encompassing bioengineering materials compatible with islet transplantation have been developed and tested (143-146). Biocompatible and biomimetic biomaterials such as hydrogels have been developed from Extracellular matrix (ECM)-based natural polymers such as collagen, fibronectin, fibrin, laminin, and alginate, and synthetic polymers such as polyethylene glycol (PEG), PGA, polyvinyl alcohol (PVA) and dextran. These biomaterials can be specifically designed to exhibit precise and tunable mechanical (stiffness), biological (incorporation of growth factors and bioactive cues) and biochemical (degradability, sensitivity to enzyme, cell adhesion) properties, to achieve a desired biological outcome. In addition, they can exhibit pro-angiogenic properties and promote the formation of vessels in the subcutaneous niche. Biomaterials can be engineered to accommodate not only pancreatic islets but also other cell types, such as hADSCs which can significantly improve transplantation outcomes. These biomaterials can be used to coat pancreatic islets, termed as micro/microencapsulation, or further developed into an implantable bulk scaffold that can allow for the exchange of nutrients throughout the hydrogel and to the encapsulated islets. Simultaneously hADSCs can act as a physical barrier to protect the islets from immune cells. Vlahos et al. developed a collagen-based hydrogel coated with endothelial cells (80). These collagen-based hydrogels were transplanted to create subcutaneous vascularized tissue implants. They showed that vascularization can be completed within 14-21 days and reverses hyperglycemia in approximately 10 days after transplantation. Another pro-angiogenic strategy they used focus on hADSCs and endothelial cells within collagen scaffolds. However, this study did not examine graft viability beyond 21 days. In 2015, Pepper et al. reported the development of a deviceless transplantation strategy for islet transplantation (78) in which they used biomedical-grade nylon catheters inserted subcutaneously and left for 30 days in order to create a transplantation site cavity in which they transplanted islets after removal of the catheters. There was no significant development of mature fibrotic scarring prior to implantation of islets by utilizing natural foreign body innate immune response. Using syngeneic, as well as immune-compromised mouse models of T1D, they showed that normoglycemia could be achieved in $91 \%$ of the mice for over 100 days using islets from both mice and humans. In contrast, Kim et al. on the other hand used esterified collagen along with heparin and hADSCs for their islet transplantation into the subcutaneous space of NOD mice (84) and found that this system improves normoglycemia better than with native collagen alone. Interestingly, they also showed that this effect is dosage-dependent on hADSCs, indicating that hADSCs or factors secreted by hADSCs is a contributing factor to survival and vascularization of transplanted islets. Yu et al. reported that the islet viability matrix (IVM) consisting of a mixture of collagen 1, L-Glutamine, fetal bovine serum, sodium bicarbonate and medium promotes islet survival for more than 150 days when transplanted subcutaneously in diabetic and immunodeficient mice (85). However, when applied to NHP 
models, the system failed to achieve euglycemia as they remained diabetic and required exogenous insulin despite the presence of insulin and glucagon positive islets and absence of fibrosis or mononuclear cell infiltration.

The skin is considered one of the largest organs in the body and one major advantage of subcutaneous transplantation is the potential availability of countless sites for transplantation. However, not all subcutaneous spaces present the same benefits as some might be more vascularized than others. Yasunami et al. performed subcutaneous islet transplantation in inguinal subcutaneous white adipose tissue, which has a feeding vessel from the inferior epigastric artery and vein (81). Their approach induced normoglycemia with 200 syngeneic islets (the number of islets that can be isolated from a single donor) equivalent in streptozotocin (STZ)-induced diabetic mice.

The subcutaneous site is an ideal transplantation site when combined with macro devices. Wang et al. demonstrated that a nanofiber-integrated (NICE) device enabled the reduction of the fibrotic response and allogenic response in FVB islet transplantation in $\mathrm{C} 57 \mathrm{BL} / 6 \mathrm{~J}$ recipient mice (87). In addition, the NICE device protected 2,500 clusters of human pluripotent stem cell-derived functional $\beta$ cells (sc- $\beta$ cells) from xenograft rejection and achieved normal glycemia for more than 30 days in immunecompetent $\mathrm{C} 57 \mathrm{BL} / 6 \mathrm{~J}$ mice (87). Inadequate oxygenation at subcutaneous space is another factor limit the viability of transplanted islets. Recently, Wang et al. demonstrated that Inverse breathing Encapsulation Devise (iBED), a silicon-based gas exchangeable materials improves oxygen $\left(\mathrm{O}_{2}\right)$ delivery is encapsulated islets and shows prolonged survival in multiple xenograft models (88). Challenge of transplantation of these islets with macro-and micro-encapsulation methods at subcutaneous sites still remain present as more islets ( $>2-5$ times) are required to achieve normal glycemia with devices compared to naked transplantation.

Subcutaneous transplantation of islet remains very attractive when combined with angiogenic and immune-modulating biomaterials. However, clinical studies of such strategies have yet show definitive proof that islets can be sustained in long-term better than intraportal transplantation. The major reason for suboptimal performance is the subcutaneous immune response in which macro- and micro-encapsulated islets are often encased by fibrotic cells, cutting off the transplanted islet from oxygen and nutrition. Supposed immune-protective devices that physically separates the transplanted islets from immune cells, which underestimates the effect of diffusible immune factors on the functionality of islets. Such is the case for the device called Theracyte ${ }^{\mathrm{TM}}$ developed in the 1990s that utilized microencapsulated islets. The device was a sealed double-membrane device that show promise in murine studies but failed to achieve normoglycemia in higher mammalian models due to fibrotic overgrowth (147-150). A similar clinical study is currently ongoing utilizing Sernova cell pouch to create a subcutaneous microenvironment that can accommodate islet transplantation (NCT03513939). The patients will be in full systemic immune-suppression, indicating that immune-modulating function for subcutaneous transplantation of current devices still need further development.
Further investigation on advanced biomaterials with not only angiogenic ability but also immune-modulating capabilities for subcutaneous islet transplantation may be needed to achieve long-term islet survival.

\section{Omentum Transplantation Site}

The omentum is a large, flat, thin adipose layer that hangs down from the stomach to cover the intra-organs (151). Due to the nature of superior neovascularization, tissue regeneration characteristics, hematostasis, and immune privilege, the omentum is considered an ideal nest for transplanted islets. Baidal et al. reported that islet transplantation in the omentum promoted long-term human islet survival and glycemic control in T1D patients and restored euglycemia and insulin independence more than 12 months (152). The trial is still ongoing and the data from longer term follow-up and recruiting more patients are required to assess longterm safety and efficacy of islet transplantation in omentum site.

The omentum can store a large amount of adipose tissue, including ADSCs; therefore, it provides a flat nest for immune cells, including macrophages, B-lymphocytes, T-lymphocytes, and mast cells, which wrap infection sites or wound tissues to protect vital organ activities $(151,153,154)$. Although the omentum possesses a large number of immune cells, the immune responses of grafted islets here are lower than those of the subcutaneous sites (89). Weaver et al. demonstrated that in leukocyte density CD45+ or CD11b+ cells 4 weeks after mouse islet transplantation with a VEGF-conjugated hydrogel was significantly lower in the epidermal fat pad, which is considered a rodent omentum compared to that of the subcutaneous site in C57BL/6J mice (89). In addition, islets transplanted in the epidermal fat site have lower, controlled glucose levels compared to those transplanted at the subcutaneous site (89). Bochenek et al. demonstrated that alginate encapsulated islets transplanted into the omentum bursa of macaques are protected from allogenic rejection and sustain glucose responsiveness more than 4 months (92). With its extensive vascularization, immune modulation, easy accessibility, and non-vital site status, the omentum is considered one of the most attractive islet transplantation sites.

Ultimately, the goal of islet transplantation research using the omentum site is to restore insulin production in diabetes patients without the need for immunosuppressive drugs. Further study is needed to investigate whether the omentum can promote longterm survival and safety of stem cell-derived islets $(43,155)$. The comparison of immune cell contribution in each transplantation sites include omentum are shown in Figure 2.

\section{Spleen Transplantation Sites}

Spleen is a peripheral lymphoid organ that has functions for maturation of adaptive immune cells including B cells, $\mathrm{T}$ cells, plasma cells and production of immunoglobulin. It is highly vascularized and drains into the portal venous system, making it a potential candidate nest for islet transplantation. Spleen is involved in the regulation of autoimmunity, as well as in the suppression of $\mathrm{T}$ cell proliferation by induction of immune tolerance. In a study by Ryu et al. in 2001 demonstrated that normal splenocytes with partially or fully matched for MHC 
class I antigens restores self-tolerance and eliminates $\beta$-cell directed autoimmunity in NOD mice $(156,157)$. Spleen also contains Regulatory $\mathrm{T}$-cells (Tregs) that suppress $\mathrm{T}$ cell proliferation, as well as dendritic cells that secrete suppressor cytokines including TGF- $\beta$, IL-10, and IL-35 which further contributes to the induction of immune tolerance (158-161). These characteristics of spleen therefore could potentially contribute to the better engraftment and long-term survival of islet transplants.

Despite above advantages, islet transplantation in the spleen sites is still controversial. A study by Stokes et al. in 2017 showed that porcine islet transplantation into the pig spleen is not significantly better than transplantation into the kidney capsule or liver, rather it is inferior to the kidney capsule according to the glucose tolerance test (GTT) results (95). Similar results were obtained when the same authors performed transplantation experiments of murine and human islets unto murine subjects at different transplantation sites - their results showed poor engraftment into the spleen, when compared to portal vein transplantation (96). And yet, a study by Itoh et al, in 2017 showed that minimum mass of syngeneic islet needed for transplantation into spleen splenic pulp is around 50 IEQ, compared to 200 IEQ in portal vein, and 1,000 IEQ in kidney capsule is needed to mitigate hyperglycemia, indicating that transplantation into the spleen can be achieved and at certain conditions, can function better than transplantation into intraportal vein or kidney (94). This contradiction in experimental outcomes makes it hard to assess the utility of

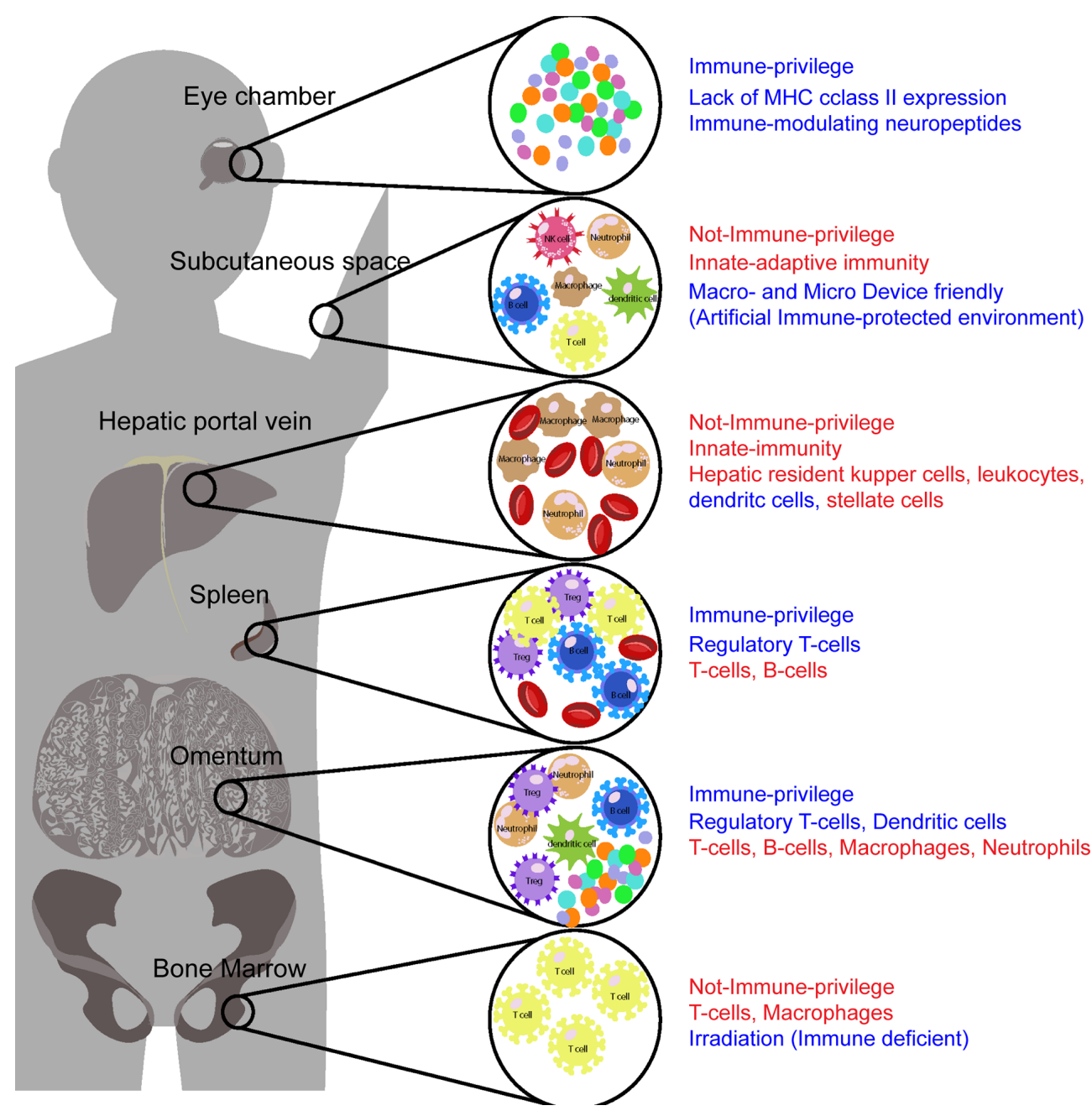

FIGURE 2 | Major immune components in each site affecting success of transplantation. Each islet transplantation sites have different microenvironment, which include immune system components that either increase or decrease of islet engraftment. Some of these sites, such as the omentum, spleen and anterior chamber of the eye, are considered immune-privileged. The presence of anti-inflammatory factors and regulatory T-cells that suppress expansion of effector T-cells and decreasing the effects of proinflammatory cytokines are key immune modulators in immune privilege sites. Other sites, such as the subcutaneous space and the bone marrow sites contain T cells and NK cells, among other immune cells that contribute to graft rejection and long-term viability of transplanted islets. Strategies must be incorporated in these sites to not only increase angiogenesis but also modulate immune responses to prevent graft rejection. The potential anti-inflammatory components in each site are described by blue color and the potential inflammatory components in each site are described by red color. 
spleen as an islet transplantation site. However, an explanation to the outcome differences may be from differences in surgical procedure and transplantation techniques wherein islet engraftment can be surmised to have low efficiency if islets are introduced to the spleen via the blood vessels or through the pulp since the environment would contain red blood cells and coagulation factors similar to hepatic portal vein and thus would induce IBMIR and lead to islet loss. Avoiding damaging the spleen and minimizing islet contact with the blood by transplantation into spleen subcapsular space may increase the engraftment efficiency but this has yet to be demonstrated in higher mammalian models (162). The difficulty of the surgical procedure and limited subcapsular space available make transplantation into the spleen challenging. Nevertheless, advancement in surgical techniques can expand the potential of spleen as a transplantation site.

The spleen is considered as not only nest for islet transplantation but also as a source of stem cells that can be differentiate into insulin producing cell which may have utility in regeneration of pancreatic $\beta$ cells $(163,164)$. A study by Kodama et al. in 2003 showed that CD45- splenocytes can develop into stem cells and further differentiate into islet progenitor cells (156). A study by Itoh et al. in 2017 further provide evidence that at islet graft expansion can occur when transplanted in the spleen by transplanting 25 islets into the spleen along with 100 islets in the kidney. The islet number transplanted into the spleen that is normally incapable of achieving normoglycemia. However, after 240 days, eight out of eleven mice maintained normoglycemia despite nephrectomy (94). More than just a transplantation site, spleen may therefore help with the survival, regeneration and expansion of insulin producing cells.

\section{Intramuscular Transplantation Site}

The muscles have been used as transplantation site for many decades, specifically for auto-transplantation of parathyroid glands. Auto-transplantation of parathyroid cells in between muscle fibers have been shown to have successful long-term outcomes with minimal side effects, prompting consideration of muscles as a potential transplantation site for islets.

Intramuscular transplantation offers several advantages. First, the muscles are capable of forming dense vasculature such as during exercise, with oxygen tension reaching values close to that of native pancreas. Since hypoxia and angiogenesis have been major factors affecting success of engraftment of islets, this ability to form extensive vasculature is beneficial not only for early engraftment and survival of transplanted islets but also in its long-term functionality and responsiveness to blood glucose. Secondly, surgical procedure of intramuscular implantation is relatively easy, can be done under local anesthesia with minor risks and complications. Transplantation into the muscle interstitium would minimize contact of islets with the blood and avoid IBMIR-related islet loss. Furthermore, intramuscular transplantation would allow easy retrieval, biopsy, and monitoring of engrafted islet which is a major advantage over most transplantation sites where monitoring and retrieval have been complicated by potential major tissue damage. Thirdly, islets can be transplanted in multiple muscle sites and therefore allow for multiple and repeated implantation and explantation of transplant tissue.
The muscle is therefore a very attractive site for islet transplantation but the challenge is still remaining. Similar to subcutaneous tissues without neovascularization pretreatment, the muscle microenvironment is hypoxic and early transplantation studies could not achieve normoglycemia or long term normoglycemia (165-168). Similarly, the transplantation efficacy in the muscles have been shown to be worse than that of kidney or liver (102). It is estimated that lack of neovascularization contributes greatly to the poor outcome of transplantation in the muscles. Just like subcutaneous transplantation, it is generally required for the muscle to be pre-treated to induced neovascularization before islet transplantation, with angiogenic factors and biocompatible devices. Witkowski et al. demonstrated that two weeks prior pre-treatment of alginate-based bio-scaffold containing angiogenic factors and extracellular matrix peptide motif RGD in the abdominal musculature of male Lewis rats sustained synergistic islet survival upto 60 days until removal of the islets (100). Similar experiments have been done by Tsuchiya et al, using matrigel to improve islet survival and muscular vascularization. In both of these studies, syngeneic islets were used which precludes another major factor in intramuscular formation which is the occurrence of extensive fibrosis and immune response (105). The muscle microenvironment is not immune-privileged and in the first few hours after transplantation, myocyte-derived pro-inflammatory cytokines such as IL6, IL8 and MCP-1 can be detected $(169,170)$. Pro-inflammatory cytokines are known to affect islet engraftment failure by contributing to early islet central necrosis and fibrosis. While fibrosis can be reduced by careful transplantation and pearlon-a-string arrangement of islets to avoid aggregation, this is insufficient to bring the engraftment efficiency comparable to intraportal transplantation (101).

Muscle is metabolically active and contractile organ. During exercise and similar activity, the muscle consume glucose and produce lactate. It is not yet fully investigated how anabolic and catabolic requirements of muscle might affect transplanted islets and their function (171). Similarly muscle contraction can affect blood supply and further negatively affect the function of transplanted islets. In this regard, Kim et al. investigated how denervation and creation of gastrocnemius muscle flap might be beneficial for intramuscular islet transplantation (108).

Intramuscular transplantation of islets have been investigated for clinical application, and the most notable was the autotransplantation into the brachioradialis muscle in a 7-year old patient with contraindication for liver intraportal transplantation. The transplanted islet were able to survive and the transplantation site was considered safe without any significant surgical or postsurgical complications proving the site's advantages and utility for graft monitoring and possible explantation (99). The patient was able to achieve an improvement in quality of life and glycemic control for two years although insulin independence was not achieved. In another study, four patients in which liver intraportal allo-transplantation was a contraindication, allogeneic human islets were transplanted into the brachioradialis forearm muscles. While there are no surgical complications, the transplanted islets were progressively became nonfunctional indicating the challenges of intra-muscular transplantation especially for allogeneic tissues 
(107). There is one clinical study currently ongoing in which islet, along with autologous mesenchymal stem cells are transplanted into the forearm intramuscular tissue of patients that are also undergoing kidney transplantation, to determine the immunomodulating effects of mesenchymal stem cells that could help sustain long term viability of intramuscularly transplanted islets (NCT01967186). These clinical studies highlight the need for research focusing on strategies not only to induce early neo-angiogenesis but also to minimize immune response to intramuscularly transplanted islet. We have demonstrated that stem cell-derived pancreatic organoids that are not only capable of secreting insulin in response to varying glucose concentration but are also immune evasive by modulating PD-L1 expression (43). Similarly, bio-compatible hydrogels and scaffold offer promising strategies such as a PD-L1-presenting biomaterial by Coronel et al. in which polyethylene glycol hydrogel are engineered to contain the T-cell immunomodulating protein PD-L1. While this study still make use of rapamycin in combination with the PD-L1containing hydrogel, it shows the potential of bio-compatible materials to be developed to contain immune-modulating properties. Intramuscular transplantation of islets, similar to subcutaneous space, remains an attractive option due to the site's advantages of accessibility and vascularization potential but its application is hampered by the robust immune response and short life span of allogeneic islets. Combining with further precise control of local $\beta$ cell inflammatory responses (172), islet graft survival may be enhanced. Bio-compatible materials and immune-modulating strategies may be able to overcome these limitations. Its similarity with subcutaneous space in terms of advantages but further limited by the undetermined effects of muscle microenvironment during active metabolism makes intra-muscular transplantation a secondary choice to subcutaneous space.

\section{CONCLUSIONS}

Current advances the field of islet transplantation for the treatment of diabetes focus on investigating the microenvironment of transplantation sites, including their vascularization, extracellular matrix content, and tissueresident immune cells. To date, no consensus was reached on identifying an ideal optimal islet transplantation site. An increasing amount of research is now focusing on developing

\section{REFERENCES}

1. Cho NH, Shaw JE, Karuranga S, Huang Y, da Rocha Fernandes JD, Ohlrogge AW, et al. IDF Diabetes Atlas: Global Estimates of Diabetes Prevalence for 2017 and Projections for 2045. Diabetes Res Clin Pract (2018) 138:271-81. doi: 10.1016/j.diabres.2018.02.023

2. Boyle PJ. Diabetes Mellitus and Macrovascular Disease: Mechanisms and Mediators. Am J Med (2007) 120(9 Suppl 2):S12-7. doi: 10.1016/ j.amjmed.2007.07.003

3. Ceriello A. Hyperglycaemia and the Vessel Wall: The Pathophysiological Aspects on the Atherosclerotic Burden in Patients With Diabetes. Eur J Cardiovasc Prev Rehabil (2010) 17(Suppl 1):S15-9. doi: 10.1097/01.hjr.0000368193.24732.66

4. Huang Y, Karuranga S, Malanda B, Williams DRR. Call for Data Contribution to the IDF Diabetes Atlas 9th Edition 2019. Diabetes Res Clin Pract (2018) 140:351-2. doi: 10.1016/j.diabres.2018.05.033 engineered hydrogel-based materials and macrodevices in order to create a transplantation space, protect the graft for the immune system, and promote angiogenesis. Although current advances on biomaterial approach for islet transplantation, the challenges remain to achieve normal glycemia with the optimal amounts of cadaveric human islets or human stem cell-derived islets. Each transplantation sites still lacks the ability to accommodate the long-term survival of islets. In particular, it is unclear whether aging and other physiological health conditions influence the survival of transplanted islets. In addition, although the current advances on stem cell technologies and genetic manipulation enable us to generate functional stem cell derived islets, long-term efficacy of biomaterials for encapsulating these artificial islets remains unknown. In addition, the risk of postimplantation trans-differentiation, teratoma formation, or graft invasion to other sites needs to be carefully investigated. Improving islet graft survival, engraftment, and efficacy in highly vascularized, nutrition and an oxygen-rich and immune-regulated sites remain the priority to improve long-term efficacy and safety for islet cell therapy to improve the outcomes of diabetic patients.

\section{REFERENCE STYLES}

Science, Engineering and Humanities and Social Sciences references.

\section{AUTHOR CONTRIBUTIONS}

FC, LN, and EY wrote and edited the manuscript. EY conceptualized and obtained funding for this study. All authors contributed to the article and approved the submitted version.

\section{FUNDING}

This work was supported by the funding from California Institute for Regenerative Medicine (CIRM)-DISC2 discovery award, Integrated Islet Distribution Program (IIDP) Pilot award, Allen Foundation grant, Mishima Kaiun Memorial Foundation Research award, Lundquist Institute Voucher award and CTSIUCLA awards.

5. Tan X, Lee LK, Huynh S, Pawaskar M, Rajpathak S. Sociodemographic Disparities in the Management of Type 2 Diabetes in the United States. Curr Med Res Opin (2020) 36(6):967-76. doi: 10.1080/03007995. 2020.1756764

6. Smalls BL, Ritchwood TD, Bishu KG, Egede LE. Racial/Ethnic Differences in Glycemic Control in Older Adults With Type 2 Diabetes: United States 2003-2014. Int J Environ Res Public Health (2020) 17(3):950. doi: 10.3390/ ijerph17030950

7. Shah VN, Grimsmann JM, Foster NC, Dost A, Miller KM, Pavel M, et al. Undertreatment of Cardiovascular Risk Factors in the Type 1 Diabetes Exchange Clinic Network (United States) and the Prospective Diabetes Follow-Up (Germany/Austria) Registries. Diabetes Obes Metab (2020) 22 (9):1577-85. doi: 10.1111/dom.14069

8. Rogers MAM, Wei MY, Kim C, Lee JM. Sex Differences in Autoimmune Multimorbidity in Type 1 Diabetes Mellitus and the Risk of Cardiovascular 
and Renal Disease: A Longitudinal Study in the United States, 2001-2017. J Womens Health (Larchmt) (2020) 29(4):511-9. doi: 10.1089/jwh.2019.7935

9. Rogers MAM, Kim C. Congenital Infections as Contributors to the Onset of Diabetes in Children: A Longitudinal Study in the United States, 2001-2017. Pediatr Diabetes (2020) 21(3):456-9. doi: 10.1111/pedi.12957

10. Zhu L, She ZG, Cheng X, Qin JJ, Zhang XJ, Cai J, et al. Association of Blood Glucose Control and Outcomes in Patients With COVID-19 and PreExisting Type 2 Diabetes. Cell Metab (2020) 31(6):1068-77.e3. doi: 10.1016/j.cmet.2020.04.021

11. Cheng X, Liu YM, Li H, Zhang X, Lei F, Qin JJ, et al. Metformin Is Associated With Higher Incidence of Acidosis, But Not Mortality, in Individuals With COVID-19 and Pre-Existing Type 2 Diabetes. Cell Metab (2020) 32(4):537-547 e3. doi: 10.1016/j.cmet.2020.08.013

12. Husain-Syed F, Vadasz I, Wilhelm J, Walmrath HD, Seeger W, Birk HW, et al. Immunoglobulin Deficiency as an Indicator of Disease Severity in Patients With COVID-19. Am J Physiol Lung Cell Mol Physiol (2021) 320(4): L590-9. doi: 10.1152/ajplung.00359.2020

13. Cefalu WT, Rodgers GP. COVID-19 and Metabolic Diseases: A Heightened Awareness of Health Inequities and a Renewed Focus for Research Priorities. Cell Metab (2021) 33(3):473-8. doi: 10.1016/j.cmet.2021.02.006

14. Bleich SN, Ard JD. COVID-19, Obesity, and Structural Racism: Understanding the Past and Identifying Solutions for the Future. Cell Metab (2021) 33(2):234-41. doi: 10.1016/j.cmet.2021.01.010

15. Cai J, Li H, Zhang C, Chen Z, Liu H, Lei F, et al. The Neutrophil-toLymphocyte Ratio Determines Clinical Efficacy of Corticosteroid Therapy in Patients With COVID-19. Cell Metab (2021) 33(2):258-69.e3. doi: 10.1016/ j.cmet.2021.01.002

16. Yu B, Li C, Sun Y, Wang DW. Insulin Treatment is Associated With Increased Mortality in Patients With COVID-19 and Type 2 Diabetes. Cell Metab (2021) 33 (1):65-77.e2. doi: 10.1016/j.cmet.2020.11.014

17. Li G, Chen Z, Lv Z, Li H, Chang D, Lu J. Diabetes Mellitus and COVID-19: Associations and Possible Mechanisms. Int J Endocrinol (2021) 2021:7394378. doi: 10.1155/2021/7394378

18. Nielsen-Saines K, Li E, Olivera AM, Martin-Blais R, Bulut Y. Case Report: Insulin-Dependent Diabetes Mellitus and Diabetic Keto-Acidosis in a Child With COVID-19. Front Pediatr (2021) 9:628810. doi: 10.3389/fped.2021.628810

19. Omotosho YB, Ying GW, Stolar M, Mallari AJP. COVID-19-Induced Diabetic Ketoacidosis in an Adult With Latent Autoimmune Diabetes. Cureus (2021) 13(1):e12690. doi: 10.7759/cureus.12690

20. Vitale RJ, Valtis YK, McDonnell ME, Palermo NE, Fisher NDL. Euglycemic Diabetic Ketoacidosis With COVID-19 Infection in Patients With Type 2 Diabetes Taking SGLT2 Inhibitors. AACE Clin Case Rep (2021) 7(1):10-3. doi: 10.1016/j.aace.2020.11.019

21. Kusmartseva I, Wu W, Syed F, van der Heide V, Jorgensen M, Joseph P, et al. Expression of SARS-CoV-2 Entry Factors in the Pancreas of Normal Organ Donors and Individuals With COVID-19. Cell Metab (2020) 32(6):10411051 e6. doi: 10.1016/j.cmet.2020.11.005

22. Boddu SK, Aurangabadkar G, Kuchay MS. New Onset Diabetes, Type 1 Diabetes and COVID-19. Diabetes Metab Syndr (2020) 14(6):2211-7. doi: $10.1016 /$ j.dsx.2020.11.012

23. Taneera J, El-Huneidi W, Hamad M, Mohammed AK, Elaraby E, Hachim MY. Expression Profile of SARS-CoV-2 Host Receptors in Human Pancreatic Islets Revealed Upregulation of ACE2 in Diabetic Donors. Biol (Basel) (2020) 9(8):215. doi: 10.3390/biology9080215

24. Coate KC, Cha J, Shrestha S, Wang W, Goncalves LM, Almaca J, et al. SARSCoV-2 Cell Entry Factors ACE2 and TMPRSS2 Are Expressed in the Microvasculature and Ducts of Human Pancreas But Are Not Enriched in Beta Cells. Cell Metab (2020) 32(6):1028-40.e4. doi: 10.1016/j.cmet.2020.11.006

25. Codo AC, Davanzo GG, Monteiro LB, de Souza GF, Muraro SP, Virgilio-daSilva JV, et al. Elevated Glucose Levels Favor SARS-CoV-2 Infection and Monocyte Response Through a HIF-1alpha/Glycolysis-Dependent Axis. Cell Metab (2020) 32(3):498-9. doi: 10.1016/j.cmet.2020.07.015

26. Tang X, Uhl S, Zhang T, Xue D, Li B, Vandana JJ, et al. SARS-CoV-2 Infection Induces Beta Cell Transdifferentiation. Cell Metab (2021) 33 (8):1577-91.e7. doi: 10.1016/j.cmet.2021.05.015

27. Wu CT, Lidsky PV, Xiao Y, Lee IT, Cheng R, Nakayama T, et al. SARS-CoV2 Infects Human Pancreatic Beta Cells and Elicits Beta Cell Impairment. Cell Metab (2021) 33(8):1565-76.e5. doi: 10.1016/j.cmet.2021.05.013
28. Hollstein T, Schulte DM, Schulz J, Gluck A, Ziegler AG, Bonifacio E, et al. Autoantibody-Negative Insulin-Dependent Diabetes Mellitus After SARSCoV-2 Infection: A Case Report. Nat Metab (2020) 2(10):1021-4. doi: 10.1038/s42255-020-00281-8

29. Montefusco L, Ben Nasr M, D’Addio F, Loretelli C, Rossi A, Pastore I, et al. Acute and Long-Term Disruption of Glycometabolic Control After SARSCoV-2 Infection. Nat Metab (2021) 3(6):774-85. doi: 10.1038/s42255-02100407-6

30. Muller JA, Gross R, Conzelmann C, Kruger J, Merle U, Steinhart J, et al. SARS-CoV-2 Infects and Replicates in Cells of the Human Endocrine and Exocrine Pancreas. Nat Metab (2021) 3(2):149-65. doi: 10.1038/s42255-02100347-1

31. Bourgeois S, Sawatani T, Van Mulders A, De Leu N, Heremans Y, Heimberg $\mathrm{H}$, et al. Towards a Functional Cure for Diabetes Using Stem Cell-Derived Beta Cells: Are We There Yet? Cells (2021) 10(1):191. doi: 10.3390/ cells10010191

32. Ricordi C, Tzakis AG, Carroll PB, Zeng YJ, Rilo HL, Alejandro R, et al. Human Islet Isolation and Allotransplantation in 22 Consecutive Cases. Transplantation (1992) 53(2):407-14. doi: 10.1097/00007890-19920201000027

33. Soon-Shiong P, Heintz RE, Merideth N, Yao QX, Yao Z, Zheng T, et al. Insulin Independence in a Type 1 Diabetic Patient After Encapsulated Islet Transplantation. Lancet (1994) 343(8903):950-1. doi: 10.1016/s0140-6736 (94)90067-1

34. Luzi L, Hering BJ, Socci C, Raptis G, Battezzati A, Terruzzi I, et al. Metabolic Effects of Successful Intraportal Islet Transplantation in Insulin-Dependent Diabetes Mellitus. J Clin Invest (1996) 97(11):2611-8. doi: 10.1172/ JCI118710

35. Shapiro AM, Lakey JR, Ryan EA, Korbutt GS, Toth E, Warnock GL, et al. Islet Transplantation in Seven Patients With Type 1 Diabetes Mellitus Using a Glucocorticoid-Free Immunosuppressive Regimen. N Engl J Med (2000) 343(4):230-8. doi: 10.1056/NEJM200007273430401

36. Nakamura T, Fujikura J, Anazawa T, Ito R, Ogura M, Okajima H, et al. Long-Term Outcome of Islet Transplantation on Insulin-Dependent Diabetes Mellitus: An Observational Cohort Study. J Diabetes Investig (2020) 11(2):363-72. doi: 10.1111/jdi.13128

37. Luzi L, Perseghin G, Brendel MD, Terruzzi I, Battezzati A, Eckhard M, et al. Metabolic Effects of Restoring Partial Beta-Cell Function After Islet Allotransplantation in Type 1 Diabetic Patients. Diabetes (2001) 50 (2):277-82. doi: 10.2337/diabetes.50.2.277

38. Warnock GL, Thompson DM, Meloche RM, Shapiro RJ, Ao Z, Keown P, et al. A Multi-Year Analysis of Islet Transplantation Compared With Intensive Medical Therapy on Progression of Complications in Type 1 Diabetes. Transplantation (2008) 86(12):1762-6. doi: 10.1097/TP.0b013e318190b052

39. Pagliuca FW, Millman JR, Gurtler M, Segel M, Van Dervort A, Ryu JH, et al. Generation of Functional Human Pancreatic Beta Cells In Vitro. Cell (2014) 159(2):428-39. doi: 10.1016/j.cell.2014.09.040

40. Rezania A, Bruin JE, Arora P, Rubin A, Batushansky I, Asadi A, et al. Reversal of Diabetes With Insulin-Producing Cells Derived In Vitro From Human Pluripotent Stem Cells. Nat Biotechnol (2014) 32(11):1121-33. doi: $10.1038 /$ nbt.3033

41. Russ HA, Parent AV, Ringler JJ, Hennings TG, Nair GG, Shveygert M, et al. Controlled Induction of Human Pancreatic Progenitors Produces Functional Beta-Like Cells in Vitro. EMBO J (2015) 34(13):1759-72. doi: 10.15252/embj.201591058

42. Yoshihara E, Wei Z, Lin CS, Fang S, Ahmadian M, Kida Y, et al. Errgamma is Required for the Metabolic Maturation of Therapeutically Functional Glucose-Responsive Beta Cells. Cell Metab (2016) 23(4):622-34. doi: 10.1016/j.cmet.2016.03.005

43. Yoshihara E, O'Connor C, Gasser E, Wei Z, Oh TG, Tseng TW, et al. Immune-Evasive Human Islet-Like Organoids Ameliorate Diabetes. Nature (2020) 586(7830):606-11. doi: 10.1038/s41586-020-2631-z

44. Velazco-Cruz L, Song J, Maxwell KG, Goedegebuure MM, Augsornworawat P, Hogrebe NJ, et al. Acquisition of Dynamic Function in Human Stem CellDerived Beta Cells. Stem Cell Rep (2019) 12(2):351-65. doi: 10.1016/ j.stemcr.2018.12.012

45. Nair GG, Liu JS, Russ HA, Tran S, Saxton MS, Chen R, et al. Recapitulating Endocrine Cell Clustering in Culture Promotes Maturation of Human Stem- 
Cell-Derived Beta Cells. Nat Cell Biol (2019) 21(2):263-74. doi: 10.1038/ s41556-018-0271-4

46. Melton D. The Promise of Stem Cell-Derived Islet Replacement Therapy. Diabetologia (2021) 64(5):1030-6. doi: 10.1007/s00125-020-05367-2

47. Balboa D, Iworima DG, Kieffer TJ. Human Pluripotent Stem Cells to Model Islet Defects in Diabetes. Front Endocrinol (Lausanne) (2021) 12:642152. doi: $10.3389 /$ fendo.2021.642152

48. Maxwell KG, Millman JR. Applications of Ipsc-Derived Beta Cells From Patients With Diabetes. Cell Rep Med (2021) 2(4):100238. doi: 10.1016/ j.xcrm.2021.100238

49. Hering BJ, Kandaswamy R, Ansite JD, Eckman PM, Nakano M, Sawada T, et al. Single-Donor, Marginal-Dose Islet Transplantation in Patients With Type 1 Diabetes. JAMA (2005) 293(7):830-5. doi: 10.1001/jama.293.7.830

50. Hering BJ, Clarke WR, Bridges ND, Eggerman TL, Alejandro R, Bellin MD, et al. Phase 3 Trial of Transplantation of Human Islets in Type 1 Diabetes Complicated by Severe Hypoglycemia. Diabetes Care (2016) 39(7):1230-40. doi: $10.2337 / \mathrm{dc} 15-1988$

51. Chang CA, Lawrence MC, Naziruddin B. Current Issues in Allogeneic Islet Transplantation. Curr Opin Organ Transplant (2017) 22(5):437-43. doi: 10.1097/MOT.0000000000000448

52. Hilbrands R, Huurman VA, Gillard P, Velthuis JH, De Waele M, Mathieu C, et al. Differences in Baseline Lymphocyte Counts and Autoreactivity are Associated With Differences in Outcome of Islet Cell Transplantation in Type 1 Diabetic Patients. Diabetes (2009) 58(10):2267-76. doi: 10.2337/db09-0160

53. Delaune V, Berney T, Lacotte S, Toso C. Intraportal Islet Transplantation: The Impact of the Liver Microenvironment. Transpl Int (2017) 30(3):22738. doi: $10.1111 /$ tri.12919

54. Bucher P, Mathe Z, Morel P, Bosco D, Andres A, Kurfuest M, et al. Assessment of a Novel Two-Component Enzyme Preparation for Human Islet Isolation and Transplantation. Transplantation (2005) 79(1):91-7. doi: 10.1097/01.tp.0000147344.73915.c8

55. Szot GL, Lee MR, Tavakol MM, Lang J, Dekovic F, Kerlan RK, et al. Successful Clinical Islet Isolation Using a GMP-Manufactured Collagenase and Neutral Protease. Transplantation (2009) 88(6):753-6. doi: 10.1097/TP.0b013e3181b443ae

56. Ricordi C, Lacy PE, Finke EH, Olack BJ, Scharp DW. Automated Method for Isolation of Human Pancreatic Islets. Diabetes (1988) 37(4):413-20. doi: $10.2337 /$ diab.37.4.413

57. Sutherland DE, Gruessner AC, Carlson AM, Blondet JJ, Balamurugan AN, Reigstad KF, et al. Islet Autotransplant Outcomes After Total Pancreatectomy: A Contrast to Islet Allograft Outcomes. Transplantation (2008) 86(12):1799-802. doi: 10.1097/TP.0b013e31819143ec

58. Bottino R, Bertera S, Grupillo M, Melvin PR, Humar A, Mazariegos G, et al. Isolation of Human Islets for Autologous Islet Transplantation in Children and Adolescents With Chronic Pancreatitis. J Transplant (2012) 2012:642787. doi: 10.1155/2012/642787

59. Kanak MA, Takita M, Kunnathodi F, Lawrence MC, Levy MF, Naziruddin B. Inflammatory Response in Islet Transplantation. Int J Endocrinol (2014) 2014:451035. doi: 10.1155/2014/451035

60. Chung WY, Pollard CA, Kumar R, Drogemuller CJ, Naziruddin B, Stover C, et al. A Comparison of the Inflammatory Response Following Autologous Compared With Allogenic Islet Cell Transplantation. Ann Transl Med (2021) 9(2):98. doi: 10.21037/atm-20-3519

61. Davalli AM, Ogawa Y, Ricordi C, Scharp DW, Bonner-Weir S, Weir GC. A Selective Decrease in the Beta Cell Mass of Human Islets Transplanted Into Diabetic Nude Mice. Transplantation (1995) 59(6):817-20. doi: 10.1097/ 00007890-199503000-00003

62. Davalli AM, Scaglia L, Zangen DH, Hollister J, Bonner-Weir S, Weir GC. Vulnerability of Islets in the Immediate Posttransplantation Period. Dynamic Changes in Structure and Function. Diabetes (1996) 45(9):11617. doi: $10.2337 /$ diab. 45.9 .1161

63. Faleo G, Russ HA, Wisel S, Parent AV, Nguyen V, Nair GG, et al. Mitigating Ischemic Injury of Stem Cell-Derived Insulin-Producing Cells After Transplant. Stem Cell Rep (2017) 9(3):807-19. doi: 10.1016/j.stemcr.2017.07.012

64. Rickels MR, Robertson RP. Pancreatic Islet Transplantation in Humans: Recent Progress and Future Directions. Endocr Rev (2019) 40(2):631-68. doi: 10.1210/er.2018-00154

65. Chen C, Chmelova H, Cohrs CM, Chouinard JA, Jahn SR, Stertmann J, et al. Alterations In Beta-Cell Calcium Dynamics and Efficacy Outweigh Islet
Mass Adaptation in Compensation of Insulin Resistance and Prediabetes Onset. Diabetes (2016) 65(9):2676-85. doi: 10.2337/db15-1718

66. Rodriguez-Diaz R, Speier S, Molano RD, Formoso A, Gans I, Abdulreda $\mathrm{MH}$, et al. Noninvasive In Vivo Model Demonstrating the Effects of Autonomic Innervation on Pancreatic Islet Function. Proc Natl Acad Sci USA (2012) 109(52):21456-61. doi: 10.1073/pnas.1211659110

67. Nyqvist D, Speier S, Rodriguez-Diaz R, Molano RD, Lipovsek S, Rupnik M, et al. Donor Islet Endothelial Cells in Pancreatic Islet Revascularization. Diabetes (2011) 60(10):2571-7. doi: 10.2337/db10-1711

68. Mojibian M, Harder B, Hurlburt A, Bruin JE, Asadi A, Kieffer TJ. Implanted Islets in the Anterior Chamber of the Eye are Prone to Autoimmune Attack in a Mouse Model of Diabetes. Diabetologia (2013) 56(10):2213-21. doi: 10.1007/s00125-013-3004-z

69. van Krieken PP, Voznesenskaya A, Dicker A, Xiong Y, Park JH, Lee JI, et al. Translational Assessment of a Genetic Engineering Methodology to Improve Islet Function for Transplantation. EBioMedicine (2019) 45:529-41. doi: 10.1016/j.ebiom.2019.06.045

70. Almaca J, Molina J, Arrojo EDR, Abdulreda MH, Jeon WB, Berggren PO, et al. Young Capillary Vessels Rejuvenate Aged Pancreatic Islets. Proc Natl Acad Sci USA (2014) 111(49):17612-7. doi: 10.1073/pnas.1414053111

71. Perez VL, Caicedo A, Berman DM, Arrieta E, Abdulreda MH, RodriguezDiaz R, et al. The Anterior Chamber of the Eye as a Clinical Transplantation Site for the Treatment of Diabetes: A Study in a Baboon Model of Diabetes. Diabetologia (2011) 54(5):1121-6. doi: 10.1007/s00125-011-2091-y

72. Tun SBB, Chua M, Hasan R, Kohler M, Zheng X, Ali Y, et al. Islet Transplantation to the Anterior Chamber of the Eye-a Future Treatment Option for InsulinDeficient Type-2 Diabetics? A Case Report From a Nonhuman Type-2 Diabetic Primate. Cell Transplant (2020) 29:963689720913256. doi: 10.1177/ 0963689720913256

73. Cantarelli E, Melzi R, Mercalli A, Sordi V, Ferrari G, Lederer CW, et al. Bone Marrow as an Alternative Site for Islet Transplantation. Blood (2009) 114 (20):4566-74. doi: 10.1182/blood-2009-03-209973

74. Maffi P, Balzano G, Ponzoni M, Nano R, Sordi V, Melzi R, et al. Autologous Pancreatic Islet Transplantation in Human Bone Marrow. Diabetes (2013) 62(10):3523-31. doi: 10.2337/db13-0465

75. Maffi P, Nano R, Monti P, Melzi R, Sordi V, Mercalli A, et al. Islet Allotransplantation in the Bone Marrow of Patients With Type 1 Diabetes: A Pilot Randomized Trial. Transplantation (2019) 103(4):83951. doi: 10.1097/TP.0000000000002416

76. Pellegrini S, Cantarelli E, Citro A, Incerti E, Piemonti L, Sordi V. Selective Local Irradiation Improves Islet Engraftment and Survival in Intra-Bone Marrow Islet Transplantation. Cytotherapy (2019) 21(10):1025-32. doi: 10.1016/j.jcyt.2019.07.005

77. Veriter S, Gianello P, Igarashi Y, Beaurin G, Ghyselinck A, Aouassar N, et al. Improvement of Subcutaneous Bioartificial Pancreas Vascularization and Function by Coencapsulation of Pig Islets and Mesenchymal Stem Cells in Primates. Cell Transplant (2014) 23(11):1349-64. doi: 10.3727/096368913X663550

78. Pepper AR, Gala-Lopez B, Pawlick R, Merani S, Kin T, Shapiro AM. A Prevascularized Subcutaneous Device-Less Site for Islet and Cellular Transplantation. Nat Biotechnol (2015) 33(5):518-23. doi: 10.1038/nbt.3211

79. Pepper AR, Pawlick R, Bruni A, Wink J, Rafiei Y, O’Gorman D, et al. Transplantation of Human Pancreatic Endoderm Cells Reverses Diabetes Post Transplantation in a Prevascularized Subcutaneous Site. Stem Cell Rep (2017) 8(6):1689-700. doi: 10.1016/j.stemcr.2017.05.004

80. Vlahos AE, Cober N, Sefton MV. Modular Tissue Engineering for the Vascularization of Subcutaneously Transplanted Pancreatic Islets. Proc Natl Acad Sci USA (2017) 114(35):9337-42. doi: 10.1073/pnas.1619216114

81. Yasunami Y, Nakafusa Y, Nitta N, Nakamura M, Goto M, Ono J, et al. A Novel Subcutaneous Site of Islet Transplantation Superior to the Liver. Transplantation (2018) 102(6):945-52. doi: 10.1097/TP.0000000000002162

82. Yamashita M, Adachi T, Adachi T, Ono S, Matsumura N, Maekawa K, et al. Subcutaneous Transplantation of Engineered Islet/Adipose-Derived Mesenchymal Stem Cell Sheets in Diabetic Pigs With Total Pancreatectomy. Regener Ther (2021) 16:42-52. doi: 10.1016/j.reth.2020.12.005

83. Hirabaru M, Kuroki T, Adachi T, Kitasato A, Ono S, Tanaka T, et al. A Method for Performing Islet Transplantation Using Tissue-Engineered Sheets of Islets and Mesenchymal Stem Cells. Tissue Eng Part C Methods (2015) 21(12):1205-15. doi: 10.1089/ten.TEC.2015.0035 
84. Kim YH, Ko JH, Lee S, Oh JY, Jeong GS, Park SN, et al. Long-Term Reversal of Diabetes by Subcutaneous Transplantation of Pancreatic Islet Cells and Adipose-Derived Stem Cell Sheet Using Surface-Immobilized Heparin and Engineered Collagen Scaffold. BMJ Open Diabetes Res Care (2020) 8(1). doi: 10.1136/bmjdrc-2019-001128

85. Yu M, Agarwal D, Korutla L, May CL, Wang W, Griffith NN, et al. Islet Transplantation in the Subcutaneous Space Achieves Long-Term Euglycaemia in Preclinical Models of Type 1 Diabetes. Nat Metab (2020) 2(10):1013-20. doi: 10.1038/s42255-020-0269-7

86. Vlahos AE, Kinney SM, Kingston BR, Keshavjee S, Won SY, Martyts A, et al. Endothelialized Collagen Based Pseudo-Islets Enables Tuneable Subcutaneous Diabetes Therapy. Biomaterials (2020) 232:119710. doi: 10.1016/j.biomaterials.2019.119710

87. Wang X, Maxwell KG, Wang K, Bowers DT, Flanders JA, Liu W, et al. A Nanofibrous Encapsulation Device for Safe Delivery of Insulin-Producing Cells to Treat Type 1 Diabetes. Sci Transl Med (2021) 13(596):eabb4601. doi: 10.1126/scitranslmed.abb4601

88. Wang LH, Ernst AU, Flanders JA, Liu W, Wang X, Datta AK, et al. An Inverse-Breathing Encapsulation System for Cell Delivery. Sci Adv (2021) 7 (20):eabd5835. doi: 10.1126/sciadv.abd5835

89. Weaver JD, Headen DM, Aquart J, Johnson CT, Shea LD, Shirwan H, et al. Vasculogenic Hydrogel Enhances Islet Survival, Engraftment, and Function in Leading Extrahepatic Sites. Sci $A d v$ (2017) 3(6):e1700184. doi: 10.1126/ sciadv. 1700184

90. Kriz J, Vilk G, Mazzuca DM, Toleikis PM, Foster PJ, White DJ. A Novel Technique for the Transplantation of Pancreatic Islets Within a Vascularized Device Into the Greater Omentum to Achieve Insulin Independence. Am J Surg (2012) 203(6):793-7. doi: 10.1016/j.amjsurg.2011.02.009

91. Berman DM, Molano RD, Fotino C, Ulissi U, Gimeno J, Mendez AJ, et al. Bioengineering the Endocrine Pancreas: Intraomental Islet Transplantation Within a Biologic Resorbable Scaffold. Diabetes (2016) 65(5):1350-61. doi: $10.2337 / \mathrm{db} 15-1525$

92. Bochenek MA, Veiseh O, Vegas AJ, McGarrigle JJ, Qi M, Marchese E, et al. Alginate Encapsulation as Long-Term Immune Protection of Allogeneic Pancreatic Islet Cells Transplanted Into the Omental Bursa of Macaques. Nat BioMed Eng (2018) 2(11):810-21. doi: 10.1038/s41551-018-0275-1

93. Gustavson SM, Rajotte RV, Hunkeler D, Lakey JR, Edgerton DS, Neal DW, et al. Islet Auto-Transplantation Into an Omental or Splenic Site Results in a Normal Beta Cell But Abnormal Alpha Cell Response to Mild Non-Insulin-Induced Hypoglycemia. Am J Transplant (2005) 5(10):2368-77. doi: 10.1111/j.16006143.2005.01041.x

94. Itoh T, Nishinakamura H, Kumano K, Takahashi H, Kodama S. The Spleen is an Ideal Site for Inducing Transplanted Islet Graft Expansion in Mice. PloS One (2017) 12(1):e0170899. doi: 10.1371/journal.pone.0170899

95. Stokes RA, Simond DM, Burns H, Patel AT, O'Connell PJ, Gunton JE, et al. Transplantation Sites for Porcine Islets. Diabetologia (2017) 60(10):1972-6. doi: $10.1007 / \mathrm{s} 00125-017-4363-7$

96. Stokes RA, Cheng K, Lalwani A, Swarbrick MM, Thomas HE, Loudovaris T, et al. Transplantation Sites for Human and Murine Islets. Diabetologia (2017) 60(10):1961-71. doi: 10.1007/s00125-017-4362-8

97. Li F, Lv Y, Li X, Yang Z, Guo T, Zhang J. Comparative Study of Two Different Islet Transplantation Sites in Mice: Hepatic Sinus Tract $v s$ Splenic Parenchyma. Cell Transplant (2020) 29:963689720943576. doi: 10.1177/0963689720943576

98. Buhler L, Deng S, O’Neil J, Kitamura H, Koulmanda M, Baldi A, et al. Adult Porcine Islet Transplantation in Baboons Treated With Conventional Immunosuppression or a Non-Myeloablative Regimen and CD154 Blockade. Xenotransplantation (2002) 9(1):3-13. doi: 10.1034/j.13993089.2002.1o044.x

99. Rafael E, Tibell A, Ryden M, Lundgren T, Savendahl L, Borgstrom B, et al. Intramuscular Autotransplantation of Pancreatic Islets in a 7-Year-Old Child: A 2-Year Follow-Up. Am J Transplant (2008) 8(2):458-62. doi: 10.1111/j.1600-6143.2007.02060.x

100. Witkowski P, Sondermeijer H, Hardy MA, Woodland DC, Lee K, Bhagat G, et al. Islet Grafting and Imaging in a Bioengineered Intramuscular Space. Transplantation (2009) 88(9):1065-74. doi: 10.1097/TP.0b013e3181ba2e87

101. Lund T, Korsgren O, Aursnes IA, Scholz H, Foss A. Sustained Reversal of Diabetes Following Islet Transplantation to Striated Musculature in the Rat. J Surg Res (2010) 160(1):145-54. doi: 10.1016/j.jss.2008.11.009
102. Kim HI, Yu JE, Park CG, Kim SJ. Comparison of Four Pancreatic Islet Implantation Sites. J Korean Med Sci (2010) 25(2):203-10. doi: 10.3346/ jkms.2010.25.2.203

103. Sterkers A, Hubert T, Gmyr V, Torres F, Baud G, Delalleau N, et al. Islet Survival and Function Following Intramuscular Autotransplantation in the Minipig. Am J Transplant (2013) 13(4):891-8. doi: 10.1111/ajt.12136

104. Wolf-van Buerck L, Schuster M, Baehr A, Mayr T, Guethoff S, Abicht J, et al. Engraftment and Reversal of Diabetes After Intramuscular Transplantation of Neonatal Porcine Islet-Like Clusters. Xenotransplantation (2015) 22 (6):443-50. doi: 10.1111/xen.12201

105. Tsuchiya H, Sakata N, Yoshimatsu G, Fukase M, Aoki T, Ishida M, et al. Extracellular Matrix and Growth Factors Improve the Efficacy of Intramuscular Islet Transplantation. PloS One (2015) 10(10):e0140910. doi: 10.1371/journal.pone.0140910

106. Espes D, Lau J, Quach M, Banerjee U, Palmer AF, Carlsson PO. Cotransplantation of Polymerized Hemoglobin Reduces Beta-Cell Hypoxia and Improves Beta-Cell Function in Intramuscular Islet Grafts. Transplantation (2015) 99(10):2077-82. doi: 10.1097/TP.0000000000000815

107. Bertuzzi F, Colussi G, Lauterio A, De Carlis L. Intramuscular Islet Allotransplantation in Type 1 Diabetes Mellitus. Eur Rev Med Pharmacol Sci (2018) 22(6):1731-6. doi: 10.26355/eurrev_201803_14588

108. Park JL, Kim T, Kim BK. Suitability of Denervated Muscle Flaps as Recipient Sites for Pancreatic Islet Cell Transplantation. Arch Plast Surg (2021) 48 (1):133-43. doi: 10.5999/aps.2020.01865

109. Brown J, Mullen Y, Clark WR, Molnar IG, Heininger D. Importance of Hepatic Portal Circulation for Insulin Action in Streptozotocin-Diabetic Rats Transplanted With Fetal Pancreases. J Clin Invest (1979) 64(6):1688-94. doi: $10.1172 / J C I 109631$

110. Shapiro AM, Ricordi C, Hering BJ, Auchincloss H, Lindblad R, Robertson $\mathrm{RP}$, et al. International Trial of the Edmonton Protocol for Islet Transplantation. N Engl J Med (2006) 355(13):1318-30. doi: 10.1056/ NEJMoa061267

111. Jansson L, Carlsson PO. Graft Vascular Function After Transplantation of Pancreatic Islets. Diabetologia (2002) 45(6):749-63. doi: 10.1007/s00125002-0827-4

112. Olsson R, Olerud J, Pettersson U, Carlsson PO. Increased Numbers of LowOxygenated Pancreatic Islets After Intraportal Islet Transplantation. Diabetes (2011) 60(9):2350-3. doi: 10.2337/db09-0490

113. Wang M, Crager M, Pugazhenthi S. Modulation of Apoptosis Pathways by Oxidative Stress and Autophagy in Beta Cells. Exp Diabetes Res (2012) 2012:647914. doi: 10.1155/2012/647914

114. Keshtkar S, Kaviani M, Jabbarpour Z, Geramizadeh B, Motevaseli E, Nikeghbalian S, et al. Protective Effect of Nobiletin on Isolated Human Islets Survival and Function Against Hypoxia and Oxidative Stress-Induced Apoptosis. Sci Rep (2019) 9(1):11701. doi: 10.1038/s41598-019-48262-6

115. Kosinova L, Patikova A, Jirak D, Galisova A, Vojtiskova A, Saudek F, et al. A Novel Model for In Vivo Quantification of Immediate Liver Perfusion Impairment After Pancreatic Islet Transplantation. Islets (2019) 11(6):12940. doi: 10.1080/19382014.2019.1651164

116. Ali KF, San Martin VT, Walsh RM, Bottino R, Stevens T, Trucco M, et al. Change in Functional Beta Cell Capacity With Time Following Autologous Islet Transplantation. Pancreas (2019) 48(5):656-61. doi: 10.1097/ MPA.0000000000001315

117. Li X, Meng Q, Zhang L. The Fate of Allogeneic Pancreatic Islets Following Intraportal Transplantation: Challenges and Solutions. J Immunol Res (2018) 2018:2424586. doi: 10.1155/2018/2424586

118. Si Z, Wang X, Sun C, Kang Y, Xu J, Wang X, et al. Adipose-Derived Stem Cells: Sources, Potency, and Implications for Regenerative Therapies. BioMed Pharmacother (2019) 114:108765. doi: 10.1016/j.biopha.2019. 108765

119. Koh A, Senior P, Salam A, Kin T, Imes S, Dinyari P, et al. Insulin-Heparin Infusions Peritransplant Substantially Improve Single-Donor Clinical Islet Transplant Success. Transplantation (2010) 89(4):465-71. doi: 10.1097/ TP.0b013e3181c478fd

120. Zhou H, Sun L, Zhang S, Zhao X, Gang X, Wang G. Evaluating the Causal Role of Gut Microbiota in Type 1 Diabetes and Its Possible Pathogenic Mechanisms. Front Endocrinol (Lausanne) (2020) 11:125. doi: 10.3389/ fendo. 2020.00125 
121. Vaarala O. Human Intestinal Microbiota and Type 1 Diabetes. Curr Diabetes Rep (2013) 13(5):601-7. doi: 10.1007/s11892-013-0409-5

122. Brown CT, Davis-Richardson AG, Giongo A, Gano KA, Crabb DB, Mukherjee N, et al. Gut Microbiome Metagenomics Analysis Suggests a Functional Model for the Development of Autoimmunity for Type 1 Diabetes. PloS One (2011) 6(10):e25792. doi: 10.1371/journal.pone.0025792

123. Towbin A. Heterologous Transplantation of Malignant Tumors to the Anterior Chamber of the Eye in Guinea Pigs Treated With Cortisone. Am J Pathol (1957) 33(3):483-97.

124. Taylor D, Seiger A, Freedman R, Olson L, Hoffer B. Electrophysiological Analysis Reinnervation of Transplants in the Anterior Chamber of the Eye by the Autonomic Ground Plexus of the Iris. Proc Natl Acad Sci USA (1978) 75(2):1009-12. doi: 10.1073/pnas.75.2.1009

125. Malmfors T, Furness JB, Campbell GR, Burnstock G. Re-Innervation of Smooth Muscle of the Vas Deferens Transplanted Into the Anterior Chamber of the Eye. J Neurobiol (1971) 2(3):193-207. doi: 10.1002/ neu. 480020302

126. Ilegems E, Berggren PO. The Eye as a Transplantation Site to Monitor Pancreatic Islet Cell Plasticity. Front Endocrinol (Lausanne) (2021) 12:652853. doi: 10.3389/fendo.2021.652853

127. Speier S, Nyqvist D, Kohler M, Caicedo A, Leibiger IB, Berggren PO. Noninvasive High-Resolution In Vivo Imaging of Cell Biology in the Anterior Chamber of the Mouse Eye. Nat Protoc (2008) 3(8):1278-86. doi: $10.1038 /$ nprot.2008.118

128. Adeghate E. Host-Graft Circulation and Vascular Morphology in Pancreatic Tissue Transplants in Rats. Anat Rec (1998) 251(4):448-59. doi: 10.1002/ (SICI) 1097-0185(199808)251:4<448::AID-AR4>3.0.CO;2-O

129. Kiba T. Relationships Between the Autonomic Nervous System and the Pancreas Including Regulation of Regeneration and Apoptosis: Recent Developments. Pancreas (2004) 29(2):e51-8. doi: 10.1097/00006676200408000-00019

130. Rosario W, Singh I, Wautlet A, Patterson C, Flak J, Becker TC, et al. The Brain-to-Pancreatic Islet Neuronal Map Reveals Differential Glucose Regulation From Distinct Hypothalamic Regions. Diabetes (2016) 65 (9):2711-23. doi: 10.2337/db15-0629

131. Taylor AW, Yee DG. Somatostatin is an Immunosuppressive Factor in Aqueous Humor. Invest Ophthalmol Vis Sci (2003) 44(6):2644-9. doi: 10.1167/iovs.02-1216

132. Taylor AW, Streilein JW, Cousins SW. Immunoreactive Vasoactive Intestinal Peptide Contributes to the Immunosuppressive Activity of Normal Aqueous Humor. J Immunol (1994) 153(3):1080-6.

133. Taylor AW, Alard P, Yee DG, Streilein JW. Aqueous Humor Induces Transforming Growth Factor-Beta (TGF-Beta)-Producing Regulatory TCells. Curr Eye Res (1997) 16(9):900-8. doi: 10.1076/ceyr.16.9.900.5043

134. Taylor AW, Streilein JW, Cousins SW. Identification of Alpha-Melanocyte Stimulating Hormone as a Potential Immunosuppressive Factor in Aqueous Humor. Curr Eye Res (1992) 11(12):1199-206. doi: 10.3109/02713689208999545

135. Streilein JW. Ocular Immune Privilege: Therapeutic Opportunities From an Experiment of Nature. Nat Rev Immunol (2003) 3(11):879-89. doi: 10.1038/ nri1224

136. Apte RS, Sinha D, Mayhew E, Wistow GJ, Niederkorn JY. Cutting Edge: Role of Macrophage Migration Inhibitory Factor in Inhibiting NK Cell Activity and Preserving Immune Privilege. J Immunol (1998) 160(12):5693-6.

137. Joo CK, Pepose JS, Stuart PM. T-Cell Mediated Responses in a Murine Model of Orthotopic Corneal Transplantation. Invest Ophthalmol Vis Sci (1995) 36 (8):1530-40.

138. Sonoda Y, Streilein JW. Orthotopic Corneal Transplantation in Mice-Evidence That the Immunogenetic Rules of Rejection Do Not Apply. Transplantation (1992) 54(4):694-704. doi: 10.1097/00007890-199210000-00026

139. Nicholls SM, Bradley BB, Easty DL. Effect of Mismatches for Major Histocompatibility Complex and Minor Antigens on Corneal Graft Rejection. Invest Ophthalmol Vis Sci (1991) 32(10):2729-34.

140. Nord C, Eriksson M, Dicker A, Eriksson A, Grong E, Ilegems E, et al. Biochemical Profiling of Diabetes Disease Progression by Multivariate Vibrational Microspectroscopy of the Pancreas. Sci Rep (2017) 7(1):6646. doi: 10.1038/s41598-017-07015-Z

141. Dombrowski F, Mathieu C, Evert M. Hepatocellular Neoplasms Induced by Low-Number Pancreatic Islet Transplants in Autoimmune Diabetic BB/Pfd Rats. Cancer Res (2006) 66(3):1833-43. doi: 10.1158/0008-5472.CAN-05-2787
142. Markmann JF, Rosen M, Siegelman ES, Soulen MC, Deng S, Barker CF, et al. Magnetic Resonance-Defined Periportal Steatosis Following Intraportal Islet Transplantation: A Functional Footprint of Islet Graft Survival? Diabetes (2003) 52(7):1591-4. doi: 10.2337/diabetes.52.7.1591

143. Sakata N, Aoki T, Yoshimatsu G, Tsuchiya H, Hata T, Katayose Y, et al. Strategy for Clinical Setting in Intramuscular and Subcutaneous Islet Transplantation. Diabetes Metab Res Rev (2014) 30(1):1-10. doi: 10.1002/ dmrr.2463

144. Bowers DT, Song W, Wang LH, Ma M. Engineering the Vasculature for Islet Transplantation. Acta Biomater (2019) 95:131-51. doi: 10.1016/j.actbio.2019.05.051

145. Smink AM, de Vos P. Therapeutic Strategies for Modulating the Extracellular Matrix to Improve Pancreatic Islet Function and Survival After Transplantation. Curr Diabetes Rep (2018) 18(7):39. doi: 10.1007/s11892-018-1014-4

146. Smink AM, Faas MM, de Vos P. Toward Engineering a Novel Transplantation Site for Human Pancreatic Islets. Diabetes (2013) 62(5):1357-64. doi: 10.2337/db12-1553

147. Kumagai-Braesch M, Jacobson S, Mori H, Jia X, Takahashi T, Wernerson A, et al. The Theracyte Device Protects Against Islet Allograft Rejection in Immunized Hosts. Cell Transplant (2013) 22(7):1137-46. doi: 10.3727/ 096368912 X657486

148. Brauker J, Martinson LA, Young SK, Johnson RC. Local Inflammatory Response Around Diffusion Chambers Containing Xenografts. Nonspecific Destruction of Tissues and Decreased Local Vascularization. Transplantation (1996) 61 (12):1671-7. doi: 10.1097/00007890-199606270-00002

149. Desai T, Shea LD. Advances in Islet Encapsulation Technologies. Nat Rev Drug Discovery (2017) 16(5):367. doi: 10.1038/nrd.2017.67

150. Scharp DW, Marchetti P. Encapsulated Islets for Diabetes Therapy: History, Current Progress, and Critical Issues Requiring Solution. Adv Drug Deliv Rev (2014) 67-68:35-73. doi: 10.1016/j.addr.2013.07.018

151. Di Nicola V. Omentum a Powerful Biological Source in Regenerative Surgery. Regener Ther (2019) 11:182-91. doi: 10.1016/j.reth.2019.07.008

152. Baidal DA, Ricordi C, Berman DM, Alvarez A, Padilla N, Ciancio G, et al. Bioengineering of an Intraabdominal Endocrine Pancreas. $N$ Engl J Med (2017) 376(19):1887-9. doi: 10.1056/NEJMc1613959

153. Wijffels JF, Hendrickx RJ, Steenbergen JJ, Eestermans IL, Beelen RH. Milky Spots in the Mouse Omentum may Play an Important Role in the Origin of Peritoneal Macrophages. Res Immunol (1992) 143(4):401-9. doi: 10.1016/ s0923-2494(05)80072-0

154. Shah S, Lowery E, Braun RK, Martin A, Huang N, Medina M, et al. Cellular Basis of Tissue Regeneration by Omentum. PloS One (2012) 7(6):e38368. doi: 10.1371/journal.pone.0038368

155. Ma H, Jeppesen JF, Jaenisch R. Human T Cells Expressing a CD19 CAR-T Receptor Provide Insights Into Mechanisms of Human CD19-Positive Beta Cell Destruction. Cell Rep Med (2020) 1(6):100097. doi: 10.1016/ j.xcrm.2020.100097

156. Kodama S, Kuhtreiber W, Fujimura S, Dale EA, Faustman DL. Islet Regeneration During the Reversal of Autoimmune Diabetes in NOD Mice. Science (2003) 302(5648):1223-7. doi: 10.1126/science.1088949

157. Ryu S, Kodama S, Ryu K, Schoenfeld DA, Faustman DL. Reversal of Established Autoimmune Diabetes by Restoration of Endogenous Beta Cell Function. J Clin Invest (2001) 108(1):63-72. doi: 10.1172/JCI12335

158. Thompson HS, Harper N, Bevan DJ, Staines NA. Suppression of Collagen Induced Arthritis by Oral Administration of Type II Collagen: Changes in Immune and Arthritic Responses Mediated by Active Peripheral Suppression. Autoimmunity (1993) 16(3):189-99. doi: 10.3109/08916939308993327

159. Miller A, A. al-Sabbagh LM. Santos, M. P. Das and H. L. Weiner: Epitopes of Myelin Basic Protein That Trigger TGF-Beta Release After Oral Tolerization are Distinct From Encephalitogenic Epitopes and Mediate Epitope-Driven Bystander Suppression. J Immunol (1993) 151(12):7307-15.

160. MacDonald TT. Suppressor T Cells, Rebranded as Regulatory T Cells, Emerge From the Wilderness Bearing Surface Markers. Gut (2002) 51 (3):311-2. doi: 10.1136/gut.51.3.311

161. Nagatani K, Dohi M, To Y, Tanaka R, Okunishi K, Nakagome K, et al. Splenic Dendritic Cells Induced by Oral Antigen Administration Are Important for the Transfer of Oral Tolerance in an Experimental Model of Asthma. J Immunol (2006) 176(3):1481-9. doi: 10.4049/jimmunol.176.3.1481

162. Sakata N, Yoshimatsu G, Kodama S. The Spleen as an Optimal Site for Islet Transplantation and a Source of Mesenchymal Stem Cells. Int J Mol Sci (2018) 19(5). doi: 10.3390/ijms19051391 
163. Kodama S, Davis M, Faustman DL. Diabetes and Stem Cell Researchers Turn to the Lowly Spleen. Sci Aging Knowledge Environ (2005) 2005(3):pe2. doi: 10.1126/sageke.2005.3.pe2

164. Faustman DL, Davis M. Stem Cells in the Spleen: Therapeutic Potential for Sjogren's Syndrome, Type I Diabetes, and Other Disorders. Int J Biochem Cell Biol (2010) 42(10):1576-9. doi: 10.1016/j.biocel.2010.06.012

165. Tze WJ, Tai J. Allotransplantation of Dispersed Single Pancreatic Endocrine Cells in Diabetic Rats. Diabetes (1988) 37(4):383-92. doi: 10.2337/ diab.37.4.383

166. Simeonovic CJ, Dhall DP, Wilson JD, Lafferty KJ. A Comparative Study of Transplant Sites for Endocrine Tissue Transplantation in the Pig. Aust J Exp Biol Med Sci (1986) 64(Pt 1):37-41. doi: 10.1038/icb.1986.4

167. Axen KV, Pi-Sunyer FX. Long-Term Reversal of Streptozotocin-Induced Diabetes in Rats by Intramuscular Islet Implantation. Transplantation (1981) 31(6):439-41. doi: 10.1097/00007890-198106000-00007

168. Weber CJ, Hardy MA, Pi-Sunyer F, Zimmerman E, Reemtsma K. Tissue Culture Preservation and Intramuscular Transplantation of Pancreatic Islets. Surgery (1978) 84(1):166-74.

169. Negi S, Jetha A, Aikin R, Hasilo C, Sladek R, Paraskevas S. Analysis of BetaCell Gene Expression Reveals Inflammatory Signaling and Evidence of Dedifferentiation Following Human Islet Isolation and Culture. PloS One (2012) 7(1):e30415. doi: 10.1371/journal.pone.0030415

170. Piemonti L, Leone BE, Nano R, Saccani A, Monti P, Maffi P, et al. Human Pancreatic Islets Produce and Secrete MCP-1/CCL2: Relevance in Human Islet Transplantation. Diabetes (2002) 51(1):55-65. doi: 10.2337/ diabetes.51.1.55
171. Rabinowitz JD, Enerback S. Lactate: The Ugly Duckling of Energy Metabolism. Nat Metab (2020) 2(7):566-71. doi: 10.1038/s42255-0200243-4

172. Wei Z, Yoshihara E, He N, Hah N, Fan W, Pinto AFM, et al. Vitamin D Switches BAF Complexes to Protect Beta Cells. Cell (2018) 173(5):113549.e15. doi: 10.1016/j.cell.2018.04.013

Conflict of Interest: EY is inventor on licensed patents and patent applications related to the HILOs technology described in this manuscript.

The remaining authors declare that the research was conducted in the absence of any commercial or financial relationships that could be construed as a potential conflict of interest.

Publisher's Note: All claims expressed in this article are solely those of the authors and do not necessarily represent those of their affiliated organizations, or those of the publisher, the editors and the reviewers. Any product that may be evaluated in this article, or claim that may be made by its manufacturer, is not guaranteed or endorsed by the publisher.

Copyright (c) 2021 Cayabyab, Nih and Yoshihara. This is an open-access article distributed under the terms of the Creative Commons Attribution License (CC BY). The use, distribution or reproduction in other forums is permitted, provided the original author(s) and the copyright owner(s) are credited and that the original publication in this journal is cited, in accordance with accepted academic practice. No use, distribution or reproduction is permitted which does not comply with these terms. 